\title{
Overview of Recent Progress in Lightning Research and Lightning Protection
}

\author{
Vladimir A. Rakov, Fellow, IEEE, and Farhad Rachidi, Senior Member, IEEE
}

(Invited Paper)

\begin{abstract}
This review paper, prepared for this second special issue on lightning of the IEEE Transactions on ELECTROMAGNETIC COMPATIBILITY, summarizes major publications on lightning and lightning protection since the first special issue published in November 1998, i.e., during the last decade. The review is organized in the following five sections: lightning discharge-observations, lightning discharge-modeling, lightning occurrence characteristics/lightning locating systems, lightning electromagnetic pulse and lightning-induced effects, and protection against lightning-induced effects.
\end{abstract}

Index Terms-Lightning discharge, lightning electromagnetic pulse (LEMP), lightning-induced effects, lightning locating systems, lightning occurrence characteristics, modeling, observations, protection against lightning-induced effects.

\section{INTRODUCTION}

$\mathbf{T}$ HE FIRST special issue on lightning of the IEEE TRANSACTIONS ON ELECTROMAGNETIC COMPATIBILITY (TEMC) was published in November 1998. It was an initiative of the then Editor-in-Chief Dr. M. Kanda. Four Guest Editors, Dr. F. G. Canavero (Turin University of Technology), Dr. M. D’Amore (University of Rome "La Sapienza"), Dr. C. Mazzetti (University of Rome "La Sapienza"), and Dr. C. A. Nucci (University of Bologna), did an excellent job in preparing the first special issue. A total of 11 papers written by internationally recognized experts were included. They were grouped in four topics:

1) lightning discharge;

2) lightning occurrence characteristics;

3) lightning electromagnetic pulse (LEMP) and induced effects;

4) protection against LEMP.

The first special issue on lightning established the state of the art in the field as of 1998. Ten years have passed during which a number of significant advances have been made in our understanding of lightning processes and lightning interaction with various systems. The goal of this second special issue is to document this recent progress.

A total of 13 papers (not counting this review paper) are included in the second special issue on lightning, which are

Manuscript received February 4, 2009. First published June 2, 2009; current version published August 21, 2009. This work was supported in part by the National Science Foundation under Grant ATM-0346164 and in part by the Swiss National Science Foundation under Grant 200021-122457.

V. A. Rakov is with the Department of Electrical and Computer Engineering, University of Florida, Gainesville, FL 32611-6130 USA (e-mail: rakov@ece.ufl.edu).

F. Rachidi is with the Ecole Polytechnique Fédérale de Lausanne, Swiss Federal Institute of Technology, Lausanne 1015, Switzerland (e-mail: farhad.rachidi@epfl.ch).

Digital Object Identifier 10.1109/TEMC.2009.2019267 grouped in the following five topics:

1) lightning discharge-observations;

2) lightning discharge-modeling;

3) lightning occurrence characteristics/lightning locating systems;

4) LEMP and lightning-induced effects;

5) protection against lightning-induced effects.

Some papers could be assigned to more than one topic.

The 13 original contributions give in-depth treatment of specific aspects of recent advances in the field. This review paper is an attempt to provide a bigger picture overview of the progress, including important studies of interest to the IEEE TEMC readership that are not covered by the original contributions. This was not an easy task in view of the relatively high publication rate: about 250 peer-reviewed journal papers on various aspects of lightning, atmospheric electricity, and lightning protection per year. Additionally, six major books on lightning and its effects have been published since the first special issue:

E. M. Bazelyan and Y. P. Raizer, Lightning Physics and Lightning Protection. Bristol, U.K.: IOP, 2000, p. 325.

G. V. Cooray, Ed. 2002. The Lightning Flash. London, U.K.: Inst. Electr. Eng., 2002, p. 574.

V. A. Rakov and M. A. Uman, Lightning: Physics and Effects. Cambridge, U.K.: Cambridge Univ. Press, 2003, p. 687.

F. Rachidi and S. V. Tkachenko, Eds. Electromagnetic Field Interaction With Transmission Lines: From Classical Theory to HF Radiation Effects. Southampton, U.K.: WIT Press, 2008, p. 259.

M. A. Uman, The Art and Science of Lightning Protection. Cambridge, U.K.: Cambridge University Press, 2008, p. 254.

H. D. Betz, U. Schumann, and P. Laroche, Eds. Lightning: Principles, Instruments and Applications. New York: SpringerVerlag, 2009, p. 691.

Thus, the present overview paper is necessarily selective. Every effort has been made to give a balanced review of recent progress in lightning research and lightning protection that is of interest to the IEEE TEMC readership.

\section{LIGHTNING DISCHARGE-OBSERVATIONS}

Two types of lightning observations are reviewed here: 1) current measurements, primarily on instrumented towers and 2) measurements of electric and magnetic fields.

\section{A. Measurements of Lightning Currents}

Traditional lightning parameters needed in engineering applications include lightning peak current, maximum current 
derivative ( $d i / d t)$, average current rate of rise, current rise time, current duration, charge transfer, and action integral, all derivable from direct current measurements. Distributions of these parameters presently adopted by most lightning protection standards are based on measurements by Berger and coworkers in Switzerland [1]. More recently, direct current measurements on instrumented towers were made in Russia, South Africa, Canada, Germany, Brazil, Japan, and Austria. Important results from the Brazilian, Japanese, and Austrian studies were published during the last decade. These are briefly reviewed next. Other recent current measurements are also considered.

1) Brazil: Visacro et al. [2] presented a statistical analysis of parameters derived from lightning current measurements on the 60-m Morro do Cachimbo tower near Belo Horizonte, Brazil. A total of 31 negative downward flashes containing 80 strokes were recorded during a period of 13 years. Median peak currents for first and subsequent strokes were found to be 45 and $16 \mathrm{kA}$, respectively, higher than the corresponding values 30 and $12 \mathrm{kA}$, reported for 101 flashes containing 236 strokes by Berger et al. [1]. Possible reasons for the discrepancy include: 1 ) a relatively small sample size in Brazil; 2) dependence of lightning parameters on geographical location (Brazil versus Switzerland); and 3) different positions of current sensors on the tower at the two locations (bottom of 60-m tower in Brazil versus top of 70-m tower in Switzerland). For typical first strokes (longer rise times), the towers in question are expected to behave as electrically short objects, so that the position of current sensor should not influence measurements. On the other hand, for subsequent strokes (shorter rise times), the towers may exhibit a distributed-circuit behavior, in which case the peak current measured at the bottom of tower is expected to be more strongly influenced by the transient process in the tower compared to the peak current at the top [3]-[5]. Visacro and Silveira [6], using a hybrid electromagnetic (HEM) model and assuming a 100-m long upward connecting leader, showed that, for typical subsequent-stroke current rise times, peak currents at the top and bottom of the Morro do Cachimbo tower should be essentially the same.

2) Japan: Takami and Okabe [7] presented lightning returnstroke currents directly measured on 60 transmission-line towers (at the top) whose heights ranged from 40 to $140 \mathrm{~m}$. A total of 120 current waveforms for negative first strokes were obtained from 1994 to 2004. This is the largest sample size for negative first strokes as of today. The median peak current was $29 \mathrm{kA}$, which is similar to that reported by Berger et al. [1], although the trigger threshold in Japan $(9 \mathrm{kA})$ was higher than in Switzerland. Interestingly, initial data from this Japanese study (for 35 negative first strokes recorded in 1994-1997) yielded the median peak current of $39 \mathrm{kA}$ [8].

3) Austria: Diendorfer et al. [9] analyzed parameters of 457 upward negative flashes initiated from the 100-m Gaisberg tower in 2000-2007. Upward flashes contain only strokes that are similar to subsequent strokes in downward flashes, i.e., they do not contain first strokes initiated by downward stepped leaders. Some upward flashes contain no strokes at all, only the so-called initial-stage current. The median return-stroke peak current was $9.2 \mathrm{kA}$ ( $n=615$, the largest sample size as of today).
For the 553-m CN Tower, Canada, Hussein et al. [10] reported the median value of the initial peak of current pulses measured in 1992-2001 at the top of the tower to be $5.1 \mathrm{kA}$, which is considerably lower than for the Gaisberg tower return strokes, as well as for subsequent strokes in downward lightning and for strokes in rocket-triggered lightning [3]. The discrepancy may be due to inclusion in the Canadian sample of events with current peaks smaller than $1 \mathrm{kA}$, some of which could be associated with the so-called initial-stage pulses, not with return strokes. Miki et al. [11] presented a detailed characterization of initial-stage pulses in object-initiated (100-m Gaisberg tower, 160-m Peissenberg tower, and 200-m Fukui chimney) and rocket-triggered lightning. The Peissenberg tower data were further examined by Flache et al. [12].

4) Triggered Lightning: Schoene et al. [13] presented a statistical analysis of the salient characteristics of current waveforms for 206 return strokes in 46 rocket-triggered lightning flashes. The flashes were triggered during a variety of experiments related to the interaction of lightning with power lines that were conducted from 1999 through 2004 at Camp Blanding, FL. The return-stroke current was injected into either one of two test power lines or into the earth near a power line via a grounding system of the rocket launcher. The geometric mean return-stroke peak current was found to be $12 \mathrm{kA}$, which is consistent with those reported from other triggered lightning studies (see [14, Table I]). Further, this parameter was found not to be much influenced by either strike-object geometry or level of man-made grounding, as previously reported by Rakov et al. [15].

5) Remote Measurements: Modern lightning locating systems output peak currents estimated for each stroke using the measured magnetic radiation field peaks and distances to the ground strike point that are reported by multiple sensors [16]. The U.S. National Lightning Detection Network (NLDN) current estimation algorithm has been calibrated using groundtruth data from the triggered lightning experiments at Kennedy Space Center (KSC; 56 strokes) and at Camp Blanding, FL (88 strokes). The median value of absolute current estimation error in Camp Blanding studies (2001-2007) was 20\%, and the maximum value was 50\% [17], [18]. These results are probably applicable to subsequent strokes in natural negative lightning. No ground-truth data for the NLDN current estimates exist for first strokes in natural lightning, natural positive strokes, or subsequent strokes with peak currents exceeding $60 \mathrm{kA}$.

Rachidi et al. [19] proposed a statistical approach, in which parameters of peak current distribution are estimated from parameters of the corresponding distribution of peak fields. The procedure is model-dependent, but it does not require knowledge of return-stroke speed (which significantly influences peak fields) for each individual lightning stroke, only knowledge of its average value.

Willett et al. [20] inferred the behavior of the current above ground in 24 triggered lightning return strokes based on: 1) measured channel base current waveforms; 2) electric field waveforms measured at a distance of $5.2 \mathrm{~km}$ from the channel; and 3) the 3-D geometry of the channels derived from stereo photographs. They found that the fine structure of the electric 
field waveforms could be explained, in large part, by channel geometry.

\section{B. Measurements of Lightning Electromagnetic Fields}

Knowledge of the characteristics of electric and magnetic fields produced by lightning discharges is needed for studying the effects of the potentially deleterious coupling of lightning fields to various circuits and systems. Sensitive electronic circuits are particularly vulnerable to such effects. On the other hand, measured electric and magnetic fields can be used for estimating various lightning parameters and for testing lightning models. This section covers the following topics.

1) Wideband electric and magnetic fields produced by lightning at tens to hundreds of meters.

2) Wideband electric and magnetic fields produced by lightning at $1 \mathrm{~km}$ and beyond.

3) Electric fields in the immediate vicinity of the lightning channel core (inside the corona sheath).

1) Wideband Electric and Magnetic Fields Produced by Lightning at Tens to Hundreds of Meters: At tens to hundreds of meters from the lightning channel, the combined leader/returnstroke vertical electric field waveforms appear as asymmetric V-shaped pulses, with the trailing (return-stroke) edge of the pulse being sharper than the leading (leader) edge. The bottom of the $\mathrm{V}$ is associated with the transition from the leader to the return stroke. The amplitude of the V-shaped waveform decreases and its duration increases with increasing distance from the lightning channel. With a few exceptions, the variation of amplitude as a function of distance is close to an inverse proportionality [21], which is consistent with a more or less uniform distribution of leader charge along the bottom kilometer or so of the channel. Schoene et al. [14] presented a statistical analysis of the salient characteristics of the electric and magnetic fields and their derivatives at distances of 15 and $30 \mathrm{~m}$ from triggered lightning strokes that lowered negative charge to ground. The measurements were made during the summers of 1999 and 2000 at Camp Blanding, FL, on about 100 return strokes, although not all field quantities were successfully recorded for each stroke.

Jerauld et al. [22], using electric and magnetic field and field derivative sensors arrayed over an area of about $1 \mathrm{~km}^{2}$ at Camp Blanding, FL, measured the close fields of stepped leaders and first return strokes in 18 natural negative cloud-to-ground lightning flashes at distances to individual sensors ranging from about $100 \mathrm{~m}$ to about $1 \mathrm{~km}$. They presented a statistical characterization of close field waveforms as a function of the distance to the lightning. Statistical data are presented for the half-peak width of the stepped leader/return-stroke electric field waveform, the stepped leader electric field change, the return-stroke electric field change at 20, 100, and $1000 \mu$ s after return stroke initiation, the peak electric field derivative, the rise time of the electric field derivative waveform, and the magnetic field initial peak, largest peak, rise time, and half-peak width.

Barbosa et al. [23] measured the horizontal component of the electric field at ground level at a distance of $60 \mathrm{~m}$ from triggered lightning channels in Brazil.
2) Wideband Electric and Magnetic Fields Produced by Lightning at $1 \mathrm{~km}$ and Beyond: Most of the experimental data published during the last decade or so are concerned with initial (preliminary) breakdown processes in the cloud, compact intracloud discharges, late stages of stepped leaders, and early stages of return strokes.

a) Initial (preliminary) breakdown processes: Nag and Rakov [24] examined the characteristics of electric field pulse trains that are attributed to preliminary breakdown in negative cloud-to-ground lightning discharges in Florida, and compared them to those of similar pulse trains associated with attempted cloud-to-ground leaders [25], [26]. The largest pulses in the train can exceed in magnitude the following first return-stroke pulse. Submicrosecond-scale pulses were observed as part of pulse trains associated with cloud-to-ground discharges, but not with attempted leaders. Preliminary breakdown pulses were also studied by Nag et al. [27] and Makela et al. [28]. Hayakawa et al. [29] developed a model to simulate very high frequency (VHF)/ultrahigh frequency (UHF) radiation due to lightning preliminary breakdown processes. Gomes and Cooray [30], Gomes et al. [31], and Sharma et al. [32] examined electric field pulses produced by cloud discharges, "chaotic" pulse trains, and preliminary breakdown pulses produced by positive ground flashes, respectively. Sonnadara et al. [33] presented radiation field spectra for cloud flashes in the interval from $20 \mathrm{kHz}$ to $20 \mathrm{MHz}$. Note that the largest pulses in cloud flashes are usually associated with the initial breakdown [34] and that the "chaotic" pulse trains most often occur prior to subsequent strokes.

b) Compact intracloud discharges: Cloud lightning discharges that produce both: 1) single bipolar electric field pulses [so-called narrow bipolar pulses (NBPs)] having typical full widths of 10-25 $\mu$ s and 2) intense HF-VHF radiation bursts (much larger than those from any other cloud-to-ground or "normal" cloud discharge process) are referred to as compact intracloud discharges or energetic intracloud events. The majority of intense VHF radiation producers appear to occur in isolation (within at least tens of milliseconds) from any other lightning process, but some were found to occur prior to, during, or following cloud-to-ground or "normal" cloud lightning discharges. The term "compact intracloud discharge" was coined by Smith et al. [35] based on their inference from a simple model that the spatial extent of in-cloud process giving rise to NBP must be relatively small. They suggested a range of 300-1000 m. A detailed review of NBPs is found in [30].

Rison et al. [36] reported that peak VHF radiation from NBP sources was typically $30 \mathrm{~dB}$ stronger than that from other lightning discharge processes and corresponded to a source power in excess of $100 \mathrm{~kW}$ over a 6-MHz bandwidth centered at $63 \mathrm{MHz}$. For the event presented by Thomas et al. [37], the estimated peak source power was greater than $300 \mathrm{~kW}$.

NBPs come in either polarity with the median source heights being 13 and $18 \mathrm{~km}$ for positive and negative (physics sign convention) polarity, respectively [38]. Sharma et al. [39] observed NBPs in Sri Lanka, but not in Sweden. Since cloud tops in Swedish thunderstorms (typically $<10 \mathrm{~km}$ ) are considerably lower than in Sri Lankan ones (typically $>15 \mathrm{~km}$ ), the observed difference in occurrence of NBPs in the two locations appears 
to be consistent with the tendency for NBP sources to be located at higher altitudes.

c) Leaders and return strokes: Murray et al. [40] have analyzed the fine structure of 131 electric fields and $d E / d t$ waveforms that were radiated during the onset of first return strikes in cloud-to-ocean lightning in Florida. The fine structure included fast pulses near the beginning of the slow front, large peaks and shoulders within the slow front and during the fast transition, and very narrow peaks in integrated $d E / d t$ waveforms. Similar fine structure was observed by Jerauld et al. [41] in $d E / d t$ and $d I / d t$ waveforms produced by an unusual rocket-triggered lightning stroke, which involved a downward dart-stepped leader and a pronounced upward connecting leader.

Cooray et al. [42] examined the fine structure of electric field waveforms produced by return strokes in positive lightning striking the North Sea. Time resolution was $10 \mathrm{~ns}$ and field propagation effects were minimal. The $10 \%-90 \%$ rise time of the waveform fast transition was about $260 \mathrm{~ns}$, on average.

Lee et al. [43], [44], working in Korea, measured and characterized electric and magnetic field waveforms associated with return strokes and stepped leaders near ground. They presented data for both positive and negative lightning.

Hussein et al. [45] measured lightning electric and magnetic fields $2 \mathrm{~km}$ from the base of the 553-m CN Tower. They examined correlation between the various parameters of the field waveforms and those of causative currents measured on the tower.

Ishii et al. [46] measured electric field waveforms produced by winter lightning in Japan. The waveforms were inferred to be associated with high-current discharges to transmission-line towers.

3) Electric Fields in the Immediate Vicinity of the Lightning Channel Core (Inside the Corona Sheath): Miki et al. [47], using Pockels sensors, measured vertical and horizontal (radial) components of electric field in the immediate vicinity (within $0.1-1.6 \mathrm{~m}$ ) of the triggered lightning channel at Camp Blanding, FL. Vertical electric field pulse peaks were in the range from $176 \mathrm{kV} / \mathrm{m}$ to $1.5 \mathrm{MV} / \mathrm{m}$ (the median is $577 \mathrm{kV} / \mathrm{m}$ ), and horizontal electric field pulse peaks were in the range from $495 \mathrm{kV} / \mathrm{m}$ to $1.2 \mathrm{MV} / \mathrm{m}$ (the median is $821 \mathrm{kV} / \mathrm{m}$ ). Vertical fields and the associated currents measured at the base of a 2-m strike object were used by Jayakumar et al. [48] to compute the input power and energy, each per unit channel length and as a function of time, associated with return strokes in rocket-triggered lightning. The estimated mean input energy over the first $50 \mu$ s or so is between $10^{3}$ and $10^{4} \mathrm{~J} / \mathrm{m}$. The channel radius and resistance per unit channel length at the instance of peak power are estimated to be $0.32 \mathrm{~cm}$ and $7.5 \Omega / \mathrm{m}$, respectively. Maslowski and Rakov [49], using measured radial electric fields reported by Miki et al. [47], estimated the lightning-channel corona sheath conductivity to be of the order of $10^{-6}-10^{-5} \mathrm{~S} / \mathrm{m}$.

\section{LIGHTNING DISCHARGE-MODELING}

Rakov and Uman [50] defined four classes of lightning returnstroke models. Most published models can be assigned to one, or sometimes two, of these four classes. The classes are primarily distinguished by the type of governing equations: 1) the first class of models includes the gas dynamic models that are primarily concerned with the radial evolution of a short segment of the lightning channel and its associated shock wave. These models typically involve the solution of gas dynamic equations (sometimes called hydrodynamic equations); 2) the second class of models includes the electromagnetic models. These models involve a numerical solution of Maxwell's equations to find the current distribution along the channel; 3) the third class of models includes the distributed-circuit models that represent the lightning discharge as a transient process on a transmission line (TL) characterized by resistance $(R)$, inductance $(L)$, and capacitance $(C)$, all per unit length. The governing equations in this case are telegrapher's equations; 4) the fourth class of models includes the engineering models that can be defined as equations relating the longitudinal current along the lightning channel at any height and any time to the current at the channel origin (the origin is usually situated at ground level, but can be at the top of a tall grounded strike object [51]. The return-stroke wavefront speed in these models can be set arbitrarily, since it is one of the input parameters. Outputs of the electromagnetic, distributed-circuit, and engineering models can be directly used for the computation of electromagnetic fields. Recent work on these three types of models is reviewed next.

\section{A. Electromagnetic Models}

At the time of publication of the First Special Issue on Lightning, there was only one peer-reviewed journal paper concerned with electromagnetic modeling of lightning [52]. As of today, there are more than a dozen of journal papers (and a very large number of conference papers) on this subject. Interest in using electromagnetic models continues to grow in part because of availability of numerical codes and increased computer capabilities. In contrast with distributed-circuit and engineering models, electromagnetic return-stroke models allow a self-consistent full-wave solution for both lightning current distribution and resultant electromagnetic fields. In a recent review, Baba and Rakov [53] classified electromagnetic models in terms of the channel representation, the excitation method, and the employed numerical technique. They additionally considered the so-called HEM/circuit theory model [54], which employs electric scalar and magnetic vector potentials for taking account of electromagnetic coupling, but is formulated in terms of circuit quantities, voltages, and currents. Applications of electromagnetic models are reviewed by Baba and Rakov [55] and those of the HEM model are described by Visacro and Silveira [56] and by Visacro and Soares [57]. More recently published electromagnetic models include those of Miyazaki and Ishii [58], in which NEC-4 is employed, and of Bonyadi-Ram et al. [59], in which inductive loading is used to reproduce variation of return-stroke speed with height. Two papers in this special issue are devoted to electromagnetic models: Baba and Rakov [60] and Moosavi et al. [61].

\section{B. Distributed-Circuit Models}

During the last few years, there appears to be a renewed interest in distributed-circuit models of the lightning return stroke. 
Theethayi and Cooray [62], using a linear distributed-circuit model of the lightning return stroke, examined the influence of constant shunt conductance on characteristics of waves propagating along the lightning channel. It follows from results of their analysis that either neglecting the weakly conducting corona sheath (ignoring the radial breakdown on the lateral surface of channel core) or extending it to infinity (allowing the radial breakdown to occupy the entire upper half space) results in a propagation speed for the highest frequency components that is essentially equal to the speed of light. In a follow-up study, Cooray and Theethayi [63] modified the telegrapher's equations to include distributed current sources in order to simulate the effects of lightning-channel corona sheath. Such a model appears to be consistent with the optical observations that the return-stroke speed is considerably lower than the speed of light. A review of optical measurements of return-stroke speed and a discussion of speeds predicted by linear and nonlinear distributed-circuit models, as well as by electromagnetic models, are found in [64].

Most of the distributed-circuit models are based on the uniform TL approximation, which is not valid for a vertical conductor above ground, whose characteristic impedance increases with height, particularly near the ground surface (e.g., [65, Sec. VI]). Visacro and De Conti [66] were apparently the first to develop an $R L C$ lightning model based on a nonuniform TL approximation. In their model, $L$ was assumed to be constant, while $C$ and $R$ were each a function of time. Model-predicted electric and magnetic fields were found to be generally consistent with measurements. De Conti et al. [67] examined the influence of different equations for $R(t)$ on electric and magnetic fields.

\section{Engineering Models}

The most used engineering models can be grouped in two categories: the lumped-source (LS; also referred to as TLtype or current-propagation) models and the distributed-source (DS; also referred to as traveling-current-source-type or currentgeneration) models.

1) Duality of Engineering Models: Cooray [68] showed that any LS model, implying a lumped current source at the lightning-channel base, can be formulated in terms of sources distributed along the channel and progressively activated by the upward-moving return-stroke front. The result is an equivalent DS model. This has been previously demonstrated for one model [modified TL model with exponential current decay with height (MTLE)] by Rachidi and Nucci [69]. The approach suggested by Cooray [68] was used by Rachidi et al. [51] to generalize five engineering models in order to take into account a tall strike object. Maslowski and Rakov [70] showed that any engineering return-stroke model can be expressed, using an appropriate continuity equation, in terms of either lumped or distributed current sources with the resultant longitudinal current distribution along the channel being the same. This property can be viewed as the duality of engineering models. The conversion alters the actual corona current (if any) of the model. Cooray et al. [71] showed that in order for the model-predicted close electric fields to be consistent with measurements, the equivalent corona current should be bipolar, and the corona current waveshape at late times should be identical to that of the longitudinal current time derivative. Maslowski and Rakov [72] proposed a new formulation for LS models in which the longitudinal current at height $\mathrm{z}^{\prime}$ is expressed as the channel base current minus the overall longitudinal current change from the ground surface to $\mathrm{z}^{\prime}$.

2) Lightning Striking Tall Objects: Engineering models have been extensively applied to various studies of lightning interaction with tall (electrically long) objects. Rachidi et al. [73] have shown, using the MTLE model, that the vertical electric field and azimuthal magnetic field at a distance of $2 \mathrm{~km}$ from a 553-m-high object struck by lightning are 2.6 times larger compared to the case when the same lightning attaches to flat ground. In these calculations, excitation was accomplished by a lumped series current source. Baba and Rakov [74] have examined the electric field and magnetic field ratios for the cases of strikes to tall objects and flat ground as a function of distance from the lightning channel, current reflection coefficients at ground and at the top of the strike object, and return-stroke speed. Lightning was represented by a TL energized by a lumped voltage source [75] connected at the channel attachment point. In close proximity to the strike object, the vertical electric field is reduced relative to the flat-ground case, while the azimuthal magnetic field is either enhanced or independent of the presence of strike object. At far distances, both the electric and magnetic fields due to strikes to the tall object are enhanced relative to the flatground case. Baba and Rakov [74] estimated the typical ratio of the far fields for the strike-object and flat-ground cases (farfield enhancement factor) to be 2.3. Pavanello et al. [76], using the DS channel representation, derived expressions relating far fields and currents associated with lightning strikes to tall towers for five different engineering models. Enhancement (or both enhancement and reduction) of lightning electric and magnetic fields by a tall strike object was also discussed by Rakov [3], Baba and Rakov [53], Miyazaki and Ishii [58], Kordi et al. [77], and Bermudez et al. [78]. Baba and Rakov [79] additionally considered the presence of building at the field point. Miyazaki and Ishii [58], who used NEC-4, also discussed dependence of the far-field enhancement factor on ground conductivity. Baba and Rakov [80], who used the finite-difference time-domain (FDTD) method, showed that, for the case of finitely conducting ground, the horizontal component of close electric field is not much influenced by the presence of tall strike object. In the case of relatively poor strike-object grounding, the vertical component of close electric field may become bipolar, as discussed in detail by Mosaddeghi et al. [81] and Baba and Rakov [80].

Enhancement of far fields by tall strike objects has important implications for interpretation of lightning peak currents reported by lightning locating systems. In general, a correction factor is needed when a tall strike object is involved [76], [82]-[84].

3) Ground-Truth Testing: Schoene et al. [85] tested the TL and traveling current source (TCS) models by comparing the first microsecond of model-predicted electric and magnetic field waveforms and field derivative waveforms at 15 and $30 \mathrm{~m}$ with the corresponding measured waveforms from triggered 
lightning return strokes. The electric and magnetic fields and their derivatives were calculated using the measured current or current derivative at the channel base, an assumed returnstroke speed, and the temporal and spatial distribution of the channel current specified by the return-stroke model. The assumed speed values were $v=1 \times 10^{8} \mathrm{~m} / \mathrm{s}, v=2 \times 10^{8} \mathrm{~m} / \mathrm{s}$, and $v=2.99 \times 10^{8} \mathrm{~m} / \mathrm{s}$ (essentially the speed of light). Schoene et al. [85] conclude that the TL model works reasonably well in predicting the measured electric and magnetic fields at both 15 and $30 \mathrm{~m}$ if return-stroke speeds are chosen to be between $1 \times 10^{8}$ and $2 \times 10^{8} \mathrm{~m} / \mathrm{s}$. In general, the TL model works better in predicting the measured field derivatives than in predicting the measured fields. The TCS model does not adequately predict either the measured electric fields or the measured electric and magnetic field derivatives at 15 and $30 \mathrm{~m}$ during the first microsecond or so. Specifically, the TCS model yields a narrow spike in the electric and magnetic field waveforms, and a pronounced opposite polarity overshoot in the electric and magnetic field derivative waveforms. These features, inconsistent with measurements, are related to the fact that the distribution of charge density along the channel for this model is bipolar, which is apparently related (at least in part) to the unrealistic assumption of matched conditions at the ground in the TCS model, while short-circuit conditions are expected in most practical situations. Miyazaki and Ishii [86] found that agreement for the field derivatives predicted by the TL model can be improved if the bidirectional propagation of return-stroke waves from the junction point between the downward dart leader and upward connecting leader is included in the model.

Pavanello et al. [87] measured the vertical component of the electric field and the azimuthal component of the magnetic field produced by lightning strikes to the $\mathrm{CN}$ Tower at three distances, $2.0,16.8$, and $50.9 \mathrm{~km}$, from the tower. Measured waveforms were compared with predictions of the five engineering returnstroke models extended to include the presence of the strike object. A reasonable agreement is found for all five engineering models for the magnetic field waveforms at the three considered distances, although the peak values of the computed fields are systematically about $25 \%$ lower than measured values. None of the models was able to reproduce the early zero crossing and the narrow undershoot seen in the measured field waveforms. As far as the electric field is concerned, larger differences have been observed between simulations and measurements.

\section{LIGHTNING OCCURRENCE CHARACTERISTICS/LIGHTNING LOCATING SYSTEMS}

The primary descriptor of lightning incidence to areas is the ground flash density. This characteristic has been estimated from records of lightning flash counters and lightning locating systems. Locating lightning discharges with reasonable accuracy requires the use of multiple-station networks. The latter are by far the best available tool for mapping of ground flash density. An overview of modern lightning locating systems is given by Cummins and Murphy [16].

When a single location per cloud-to-ground lightning stroke, typically the ground strike point, is required, magnetic field di- rection finding, the time-of-arrival technique, or a combination of the two can be employed. Location errors as low as $1 \mathrm{~km}$ or less and detection efficiencies approaching $90 \%$ are possible. The U.S. NLDN, which is part of North American Lightning Detection Network (NALDN) covering the United States and Canada, is an example of a network combining both magnetic direction finding and time of arrival techniques. When electromagnetic imaging of the developing channels of any type of lightning flash is required, the VHF time-of-arrival technique [e.g., Lightning Mapping Array (LMA) or Lightning Detection and Ranging (LDAR) system] or VHF interferometry (e.g., SAFIR) can be used.

Performance characteristics of the NALDN have been recently evaluated using rocket-triggered lightning [17], [18] video recordings [88], and instrumented towers [83].

Schulz et al. [89] presented statistics for more than three million cloud-to-ground flashes reported during 1992-2001 by the Austrian lightning locating system (ALDIS). Ground flash densities in Austria were found to be between 0.5 and 4 flashes $/ \mathrm{km}^{2}$ per year.

Smith et al. [90] described a wideband time-of-arrival system, the Los Alamos Sferic Array (LASA), which consisted of five stations in New Mexico in 1998, and was expanded to 11 stations in New Mexico, Texas, Florida, and Nebraska in 1999. Each station acquired GPS-time-stamped, 12-bit records of electric field waveforms produced by various lightning processes. The record length was 8 or $16 \mathrm{~ms}$, and the sampling rate was $1 \mathrm{MHz}$. The system was later upgraded (including a 3-D capability within a $100-\mathrm{km}$ range) and expanded to better cover northcentral Florida and the Great Plains [91].

At distances greater than $1000 \mathrm{~km}$ or so, very low frequency (VLF) signals can propagate effectively in the waveguide formed by the Earth's surface and the ionosphere. Shao and Jacobson [92] considered both ground and ionosphere-reflected waves produced by lightning return strokes at distances from 200 to $1500 \mathrm{~km}$.

\section{LEMP AND LIGHTNING-INDUCED EFFECTS}

\section{A. Lightning Electromagnetic Fields}

Lightning electromagnetic fields are generally obtained by considering the lightning channel as a vertical antenna above a semiinfinite ground. Basically, three different approaches have been adopted to obtain the electromagnetic fields, both above and below the earth surface: 1) numerical solution of the exact equations through dedicated algorithms; 2) numerical solution of the Maxwell's equations using numerical methods, such as FDTD or the method of moments (MoM); and 3) use of simplified equations.

1) Use of Dedicated Algorithms: The complete problem of the electromagnetic radiation of a dipole over a finitely conducting half-space was treated by [93] solving Maxwell's equations for both media in accordance with the boundary conditions on the air-ground interface. The resulting equations involve the so-called Sommerfeld integral, which is highly oscillatory and difficult to evaluate numerically. Recently, Delfino and coworkers developed an efficient algorithm for the evaluation of the 
exact expression for both the above-ground and underground fields generated by a lightning discharge [94]-[96]. The algorithm was used, in particular, to test the validity of simplified approaches.

2) FDTD and MoM: Compared with traditional approaches for the evaluation of electromagnetic fields in the vicinity of lightning channel, the FDTD method has the advantage of being easily implemented in computer codes [97], and further, the finite ground conductivity is taken into account in a straightforward way. The 1-D FDTD method has been widely applied to the analysis of the overvoltages induced on overhead TLs by nearby lightning return strokes [98]. It is only recently that the method has also been applied to the analysis of lightning electromagnetic fields. Sartori and Cardoso [99] have proposed a hybrid method partially based on the FDTD technique for the near-electric-field calculation. The magnetic field was first determined analytically, assuming the spatial-temporal distribution of the current in each radiating dipole to be a step function. Yang et al. [100] have also used FDTD to compute electromagnetic fields in the vicinity of a return stroke. Their FDTD approach has been used as a reference to test the validity of the quasi-image method and the Cooray-Rubinstein formula. Baba and Rakov [65], [101] used the FDTD method to study the mechanisms of current wave propagation along vertical conductors [65], to reproduce small-scale experiments [101], and to study the enhancement of electromagnetic fields measured on the top of buildings [79].

It is worth noting that the MoMs is also extensively applied to obtain electromagnetic fields radiated by a lightning discharge, within the so-called antenna theory (AT) models, which belong to the class of electromagnetic models and in which the return-stroke channel is represented using thin wires [52], [77], [102]-[107]. Most of the MoM solutions are implemented in the frequency domain, which allows taking into account the presence of a lossy ground in a straightforward way.

3) Simplified Approaches: When a perfectly conducting ground is assumed, the computation of the electromagnetic fields can be greatly simplified [108]. For distances not exceeding several kilometers, the perfect ground conductivity assumption is a reasonable approximation for the vertical component of the electric field and for the azimuthal magnetic field, as shown by several authors [109]-[111]. In fact, the contributions of the source dipole and its image to these field components add constructively, and consequently, relatively small variations in the image field due to the finite ground conductivity will have little effect on the total field. However, the horizontal (radial) component of the electric field radiated by lightning is appreciably affected by the finite ground conductivity. Indeed, for this field component, the effects of the two contributions subtract, and small changes in the image field may lead to appreciable changes in the total horizontal field. Although the intensity of the horizontal field component is generally much smaller than that of the vertical one, within the context of certain field-to-TL coupling models [112], it plays an important role, and thus, its calculation requires the use of the rigorous expressions or at least their reasonable approximations. Several studies have shown that the Cooray-Rubinstein formula yields a satisfactory approximation of the above-ground horizontal electric field at close $(100 \mathrm{~m})$, intermediate (some kilometers), and far (tens of kilometers) distances [109], [111]. Delfino et al. [96] showed that only for very low conductivities, does the CoorayRubinstein formula exhibit some deviations from the reference one, but it still gives a conservative estimate of the radial field component, since it behaves as an upper bound for the exact curve. General limits of validity of the Cooray-Rubinstein approximation were theoretically examined by Wait [113]. Shoory et al. [107] presented a general equation for the horizontal electric field, from which the Cooray-Rubinstein formula can be derived as a special case. Barbosa and Paulino [114] proposed an approximate time-domain formula for the horizontal electric field whose range of validity was stated to be equivalent to that of the Cooray-Rubinstein formula (which is in the frequency domain). Caligaris et al. [115] mathematically derived the timedomain counterpart of the Cooray-Rubinstein formula.

Concerning underground electromagnetic fields, the simplified formula proposed by Cooray [116] has been shown to accurately reproduce the horizontal electric field penetrating the ground at distances as close as $100 \mathrm{~m}$ [117]. It has also been shown that predictions of the Cooray's formula are in good agreement with exact solutions for large values of ground conductivity (about $0.01 \mathrm{~S} / \mathrm{m}$ ). For poor ground conductivities (0.001 S/m or so), Cooray's expression yields less satisfactory results, especially for the late time response [94]. Underground electric and magnetic fields for strikes to both flat ground and tall towers have been calculated, using engineering return-stroke models and the FDTD method, by Mimouni et al. [118], [119].

Thottappillil and Rakov [120] compared three different approaches to the computation of lightning electric fields, including the traditional dipole (Lorentz condition) technique and two versions of the monopole (continuity equation) technique. Although the three approaches yield the same total fields, expressions for the individual electric field components in the time domain, traditionally identified by their distance dependence as electrostatic, induction, and radiation terms, are different, suggesting that explicit distance dependence is not an adequate identifier.

Thottappillil et al. [121] derived simplified expressions based on the MTLE and modified transmission line model with linear current decay with height (MTLL) models for calculating far (radiation) electric fields produced at an arbitrary altitude by lightning return strokes. It is shown that different (for example, containing either spatial or time integral), but equivalent equations can be derived for each of the models. Lightning electric fields aloft were also considered in [122] and [123].

Fernando and Cooray [124] examined propagation effects on the electric field time derivatives produced by lightning return strokes, and Cooray [125] showed that propagation effects on field pulses radiated by cloud discharges are less severe than those on return-stroke pulses. Cooray [126], using Sommerfeld's integrals, examined propagation effects on the vertical component of electric field for distances between $10 \mathrm{~m}$ and $1 \mathrm{~km}$ and for ground conductivities ranging from 0.01 to $0.001 \mathrm{~S} / \mathrm{m}$. The results were compared with predictions of various approximate theories. Cooray [127], using Sommerfeld's 
integrals, evaluated propagation effects on lightning-generated magnetic fields.

\section{B. Induced Effects on Overhead Lines}

To solve the electromagnetic coupling problem, i.e., the determination of voltages and currents induced by an external field on a conducting system, AT could be used, which is the general and rigorous approach based on Maxwell's equations [128]. Due to the length of typical overhead line installations, together with the need of modeling other system components (e.g., power transformers, surge arresters, general line terminations), the use of such theory for the calculation of lightning-induced overvoltages is not straightforward and implies long computing times. A popular approach is the use of the TL theory [129]. The basic assumptions of this approximation are that the response of the line is quasi-TEM, and that the transverse dimensions of the line are much smaller than the minimum significant wavelength. The line is represented by an infinite series of elementary sections to which, by virtue of the aforementioned assumptions, the quasi-static approximation applies. Each section is illuminated progressively by the incident electromagnetic field so that the longitudinal propagation effects are taken into account.

Different and equivalent coupling models based on the use of the TL approach have been proposed in the literature [112], [130], [131]. Among these, the model by Agrawal et al. [112] and its extensions, which take into account the presence of ground losses, have been widely applied to the analysis of lightning-induced voltages on power lines [132].

Montano et al. [133] developed an approach for the implementation of Agrawal et al.'s model in any circuit simulation software that has built-in TL models. Hoidalen [134] proposed analytical expressions for calculation of lightning-induced voltages on multiconductor overhead lines that are valid for the first few microseconds (when the peak voltage occurs), provided that the distance is between $100 \mathrm{~m}$ and $10 \mathrm{~km}$, the ground conductivity is larger than $0.001 \mathrm{~S} / \mathrm{m}$, and the line is shorter than $1 \mathrm{~km}$. Darveniza [135] suggested a practical extension of Rusck's formula for maximum lightning-induced voltages that accounts for finite ground conductivity.

There have been attempts to compute induced voltages using numerical techniques (e.g., MoM and FDTD) in electromagnetic field calculations, which do not require the Cooray-Rubinstein approximation in finding the horizontal component of electric field [136]-[139].

Michishita et al. [140] presented simultaneous measurements of lightning-induced voltages and lightning currents associated with strikes to a 200-m-tall stack. The data were compared with simulations obtained using Agrawal et al.'s coupling model [112], and in general, very good agreement was obtained.

The general expressions for the ground impedance and admittance in the frequency domain involve infinite integrals and are not appropriate for a numerical evaluation. Furthermore, they do not have analytical inverse Fourier transform to be used in a time-domain solution. Accurate approximations for the ground impedance (in the frequency domain) and the ground transient resistance (in the time domain) have been proposed (see [141] for a review).

Another topic related to lightning-induced voltages that has attracted considerable attention is the coupling to a complex system such as an electrical distribution network. In order to take into account the presence of power system components, line discontinuities, and complex system topologies, the LEMP-toTL coupling model has been linked with appropriate circuit solver software, such as the electromagnetic transient program (EMTP), taking advantage of the large available library of power system components [142]. The developed models for the calculation of LEMP-caused transients in overhead power lines have been experimentally validated using reduced scale setups with LEMP and nuclear electromagnetic pulse (NEMP) simulators, and full-scale setups illuminated by rocket-triggered lightning fields (see [142] for a review).

Theethayi et al. [143] described measurements of lightninginduced transients entering a Swedish railway facility during the summer of 2003. They reported peak-to-peak induced voltages up to 6-7 kV at the secondary terminals of the three-phase transformer. They also presented simulation results to identify the levels of induced voltages appearing at the input of the railway facility.

Borghetti et al. [144] discussed lightning-induced overvoltages transferred to low-voltage networks through distribution power transformers and analyzed the influence of the HF model adopted for the representation of the power transformer on the calculation results.

\section{Induced Effects on Buried Cables}

Petrache et al. [117] presented a review of theoretical methods to compute lightning-induced currents and voltages on buried cables. Their analysis revealed that all the proposed approximations for the ground impedance provide very similar results for the considered range of frequencies (up to $30 \mathrm{MHz}$ ). They also proposed a logarithmic approximation for the ground impedance of a buried cable and showed that, within the frequency range of interest, the wire impedance can be neglected, due to its small contribution to the overall longitudinal impedance of the line. The ground admittance, however, can play an important role at $\mathrm{HF}$ ( $1 \mathrm{MHz}$ or so), especially in the case of poor ground conductivity [117]. This is in contrast with the case of overhead lines in which its contribution is generally negligible even in the megahertz range. Paolone et al. [145] and Petrache et al. [146] presented experimental results obtained at the International Center for Lightning Research and Testing (ICLRT) at Camp Blanding, FL, during summers 2002 and 2003. Currents induced by triggered and natural lightning events were measured at the terminations of a buried power cable, in the cable shield, and in the inner cable conductor. Measurements of the horizontal component of the magnetic field above the ground surface for both natural and triggered lightning are also presented. For distant natural lightning events, locations of ground strike points were determined using the NLDN. Based on the theoretical developments presented in [117], the field-to-buried cable coupling equations are solved both in the time domain and 
in the frequency domain. The obtained experimental results are then used to test the validity of the numerical simulations.

Theethayi et al. [147] studied the behavior of the ground impedance and admittance for a frequency range up to $10 \mathrm{MHz}$ and proposed a simple, but accurate expression for the ground impedance.

Zhou et al. [148] suggested the use of digital filtering in conjunction with the FDTD method for studying electromagnetic coupling to buried cables.

Schoene et al. [149] measured currents induced in a $100 \mathrm{~m}$ $\times 30 \mathrm{~m}$ buried rectangular loop conductor (counterpoise) by natural and rocket-triggered lightning at distances ranging from tens to hundreds of meters at Camp Blanding, FL. The peak values of 12 triggered lightning channel base currents and the peak values of the induced currents in the counterpoise were strongly correlated. Direct lightning current injection into the counterpoise, which is part of a test airport lighting system, was studied experimentally by Bejleri et al. [150] and modeled by Theethayi et al. [151]. Schoene et al. [149] also measured lightning-induced currents in a grounded vertical conductor of $7 \mathrm{~m}$ height, which acted as a $d E / d t$ antenna for the first half a microsecond or so after return stroke initiation.

Theethayi et al. [152] discussed the validity of the TL approximation in the study of transients in buried wires. Their analysis showed that the TL solutions are sufficiently accurate for transients of lightning origin.

\section{PRotection AgAinst Lightning-Induced EfFEcts}

Protection of structures and systems against direct and induced effects of lightning is an important subject of many studies [153]. We have selected in this review only three specific topics that are of primary interest to the IEEE TRANSACTIONS ON EMC readership, namely, lightning protection of distribution lines, lightning protection of wind turbines, and grounding.

\section{A. Lightning Protection of Distribution Lines}

The problem of lightning protection of medium-voltage networks has been seriously reconsidered in recent years due to the proliferation of sensitive loads and the increasing demand by customers for good quality in the power supply [132]. Overvoltages due to lightning are a major cause of flashovers on overhead power distribution lines. These flashovers may cause permanent or short interruptions, as well as voltage dips, in the distribution networks. The performance analysis and protection of overhead distribution lines have been the subject of recent IEEE and International Conference on Large Electric High-Tension Systems (CIGRE)-International Conference on Electricity Distribution (CIRED) working group activities. The IEEE Working Group on the Lightning Performance of Electric Power Overhead Distribution Lines released a revised version of the IEEE guide 1410 in 2004 [154]. The guide is presently undergoing a new revision, and an updated version is expected to be released in the near future. The CIGRE-CIRED Joint Working Group C4.402 on the Protection of Medium Voltage and Low Voltage Networks against Lightning recently produced a technical brochure presenting basic principles in lightning protection [155]. Two other documents are under preparation, which will deal with the problem of lightning protection of medium-voltage and low-voltage networks.

Metwally and Heidler [156] presented a numerical analysis showing the improvement of the lightning performance of overhead TLs using passive shield wires. Paolone et al. [157] analyzed, using numerical simulations, the effect of shielding wires on the mitigation of lightning-induced voltages. They showed that the effectiveness of shielding wires depends mostly on the spacing between two adjacent grounding points, rather than on the value of the grounding resistance. They also compared their numerical simulations with results obtained using the Rusck simplified formula [158]. Their analysis suggests that the Rusck formula allows for an accurate prediction of the mitigation effect of the shielding wire only when the number of groundings is large, in agreement with Rusck's assumption that the shielding wire is at zero potential.

Based on a small-scale model experiment, Piantini and Janiszewski [159] and Piantini et al. [160] analyzed the effectiveness of surge arresters in terms of the reduction of the induced voltage magnitudes. They showed that the effectiveness of surge arresters depends on different factors. In particular, the lower the grounding resistance and the shorter the distance between two adjacent arresters, the better the performance of the arresters. The same conclusion was obtained in the theoretical study of Paolone et al. [157], in which they also showed that a low number of surge arresters may result in significant negative peaks of the induced voltage along the line.

The standard IEEE procedure to evaluate the indirect lightning strike performance of distribution lines was discussed by Borghetti et al. [161]. They proposed a new, improved procedure that takes into account the statistical distributions of the lightning current peak and rise time, as well as well as their correlation, along with the effect of finite ground conductivity and the actual configuration and topology of the distribution network.

Lightning performance of $6.6-\mathrm{kV}$ distribution lines has been the subject of field studies in Japan [162]-[164].

\section{B. Lightning Protection of Wind Turbines}

It is well known that wind turbines are vulnerable to lightning, which can cause significant damage to wind turbine components [165]-[170]. Lightning protection of traditional wind turbines has been addressed in detail in standards (see, for example, [171]). Lightning protection of modern wind turbines presents a number of new challenges due to the geometrical, electrical, and mechanical peculiarities of the turbines. Some of the salient issues related to lightning protection of long wind turbine blades were discussed in [172]. It has been shown, in particular, that the rotation of the blades may have a considerable influence on the number of strikes to modern wind turbines as these may be triggering their own lightning. Furthermore, the presence of carbon reinforced plastics (CRP) in the blades introduces a new set of problems to be dealt with in the design of the turbines' lightning protection system [172]. 


\section{Grounding}

The behavior of grounding systems at power frequencies is quite well understood. However, its modeling for lightning transients is a complex task, because it may involve both frequency dependency and nonlinearity arising from soil ionization. During the last decade, a great deal of effort has been devoted to the modeling of grounding systems at HF [173]-[182]. Specific models were developed to deal with soil ionization [183]-[187] and different numerical techniques were applied (e.g., finiteelement method [188], MoM, and arithmetic operator method [189]). A survey of modeling techniques applied to frequencydomain and transient analysis of grounding electrodes under lightning conditions is presented in [182]. The behavior of grounding systems subjected to direct lightning current injection is discussed in [150], [151], and [190]-[193].

\section{ACKNOWLEDGMENT}

The authors would like to acknowledge the support of W. Radasky (TC-5 Chair) and P. Wilson (EIC), as well as helpful comments of four anonymous reviewers.

\section{REFERENCES}

[1] K. Berger, R. B. Anderson, and H. Kroninger, "Parameters of lightning flashes," Electra, vol. 41, pp. 23-37, 1975.

[2] S. Visacro, J. A. Soares, M. A. O. Schroeder, L. C. L. Cherchiglia, and V. J. de Sousa, "Statistical analysis of lightning current parameters: Measurements at Morro do Cachimbo Station," J. Geophys. Res., vol. 109, pp. D01105-1-D01105-11, 2004.

[3] V. A. Rakov, "Transient response of a tall object to lightning," IEEE Trans. Electromagn. Compat., vol. 43, no. 4, pp. 654-661, Nov. 2001.

[4] V. A. Rakov, "A review of the interaction of lightning with tall objects," Recent Res. Develop. Geophys., vol. 5, pp. 57-71, 2003.

[5] Y. Baba and V. A. Rakov, "Influences of the presence of a tall grounded strike object and an upward connecting leader on lightning currents and electromagnetic fields," IEEE Trans. Electromagn. Compat., vol. 49, no. 4, pp. 886-892, Nov. 2007.

[6] S. Visacro and F. H. Silveira, "Lightning current waves measured at short instrumented towers: The influence of sensor position," Geophys. Res. Lett., vol. 32, pp. L18804-1-L18804-5, 2005. DOI: 10.1029/2005GL023255.

[7] J. Takami and S. Okabe, "Observational results of lightning current on transmission towers," IEEE Trans. Power Del., vol. 22, no. 1, pp. 547556, Jan. 2007.

[8] T. Narita, T. Yamada, A. Mochizuki, E. Zaima, and M. Ishii, "Observation of current waveshapes of lightning strokes on transmission towers," IEEE Trans. Power Del., vol. 15, no. 1, pp. 429-435, Jan. 2000.

[9] G. Diendorfer, H. Pichler, and M. Mair, "Some parameters of negative upward-initiated lightning to the Gaisberg tower (2000-2007)," IEEE Trans. Electromagn. Compat., vol. 51, no. 3, pp. 443-452, Aug. 2009.

[10] A. Hussein, W. Janischewskyj, M. Milewski, V. Shostak, W. A. Chisholm, and J. S. Chang, "Current waveform parameters of CN Tower," J. Electrostat., vol. 60, pp. 149-162, 2004.

[11] M. Miki, V. A. Rakov, T. Shindo, G. Diendorfer, M. Mair, F. Heidler, W. Zischank, M. A. Uman, R. Thottappillil, and D. Wang, "Initial stage in lightning initiated from tall objects and in rocket-triggered lightning," J. Geophys. Res., vol. 110, pp. D02109.1-D02109.15, 2005. DOI: $10.1029 / 2003 J D 004474$.

[12] D. Flache, V. A. Rakov, F. Heidler, W. Zischank, and R. Thottappillil, "Initial-stage pulses in upward lightning: Leader/return stroke versus Mcomponent mode of charge transfer to ground," Geophys. Res. Lett., vol. 35, pp. L13812-1-L13812-5, 2008. DOI: 10.1029/2008GL034148.

[13] J. Schoene, M. A. Uman, V. A. Rakov, K. J. Rambo, J. Jerauld, C. T. Mata, A. G. Mata, D. M. Jordan, and G. H. Schnetzer, "Characterization of return stroke currents in rocket-triggered lightning," J. Geophys. Res., vol. 114, D03106, 2009. DOI: 10.1029/2008JD009873.
[14] J. Schoene, M. A. Uman, V. A. Rakov, V. Kodali, K. J. Rambo, and G. H. Schnetzer, "Statistical characteristics of the electric and magnetic fields and their time derivatives $15 \mathrm{~m}$ and $30 \mathrm{~m}$ from triggered lightning," J. Geophys. Res., vol. 108, no. D6, 4192, 2003. DOI: 10.1029/2002JD002698.

[15] V. A. Rakov, M. A. Uman, K. J. Rambo, M. I. Fernandez, R. J. Fisher, G. H. Schnetzer, R. Thottappillil, A. Eybert-Berard, J. P. Berlandis, P. Lalande, A. Bonamy, P. Laroche, and A. Bondiou-Clergerie, "New insights into lightning processes gained from triggered-lightning experiments in Florida and Alabama," J. Geophys. Res., vol. 103, pp. 14117 $14130,1998$.

[16] K. Cummins and M. Murphy, "An overview of lightning locating systems: History, techniques, and data uses, with an in-depth look at the U.S NLDN," IEEE Trans. Electromagn. Compat., vol. 51, no. 3, pp. 499-518, Aug. 2009.

[17] J. Jerauld, V. A. Rakov, M. A. Uman, K. J. Rambo, and D. M. Jordan, "An evaluation of the performance characteristics of the U.S. National Lightning Detection Network in Florida using rocket-triggered lightning," J. Geophys. Res., vol. 110, pp. D19106-1-D19106-16, 2005. DOI: $10.1029 / 2005 J D 005924$.

[18] A. Nag, J. Jerauld, V. A. Rakov, M. A. Uman, K. J. Rambo, D. M. Jordan, B. A. DeCarlo, J. Howard, K. Cummins, and J. A. Cramer, "NLDN responses to rocket-triggered lightning at Camp Blanding, Florida, in 2004, 2005, and 2007," presented at the 29th Int. Conf. Lightning Protection (ICLP), Uppsala, Sweden, 2008.

[19] F. Rachidi, J. L. Bermudez, M. Rubinstein, and V. A. Rakov, "On the estimation of lightning peak currents from measured fields using lightning location systems," J. Electrostat., vol. 60, pp. 121-129, 2004.

[20] J. C. Willett, D. M. Le Vine, and V. P. Idone, "Lightning return stroke current waveforms aloft from measured field change, current, and channel geometry," J. Geophys. Res., vol. 113, pp. D07305-1-D07305-45, 2008 DOI: $10.1029 / 2006 J D 008116$.

[21] D. E. Crawford, V. A. Rakov, M. A. Uman, G. H. Schnetzer, K. J. Rambo M. V. Stapleton, and R. J. Fisher, "The close lightning electromagnetic environment: Dart-leader electric field change versus distance," J. Geophys. Res., vol. 106, pp. 14909-14917, 2001.

[22] J. Jerauld, M. A. Uman, V. A. Rakov, K. J. Rambo, D. M. Jordan, and G. H. Schnetzer, "Electric and magnetic fields and field derivatives from lightning stepped leaders and first return strokes measured at distances from 100 to 1000 m," J. Geophys. Res., vol. 113, D17111, 2008. DOI: 10.1029/2008JD010171.

[23] C. F. Barbosa, J. O. S. Paulino, G. C. de Miranda, W. do C. Boaventura, F E. Nalin, S. Person, and A. Zeddam, "Measured and modeled horizonta electric field from rocket-triggered lightning," IEEE Trans. Electromagn. Compat., vol. 50, no. 4, pp. 913-920, Nov. 2008

[24] A. Nag and V. A. Rakov, "Electric field pulse trains occurring prior to the first stroke in cloud-to-ground lightning," IEEE Trans. Electromagn. Compat., vol. 51, no. 1, pp. 147-150, Feb. 2009.

[25] A. Nag and V. A. Rakov, "Pulse trains characteristic of preliminary breakdown in cloud-to-ground lightning that are not followed by return stroke pulses," J. Geophys. Res., vol. 113, pp. D01102-1-D01102-12, 2008. DOI: 10.1029/2007JD008489.

[26] S. R. Sharma, V. Cooray, and M. Fernando, "Isolated breakdown activity in Swedish lightning," J. Atmos. Solar-Terr. Phys., vol. 70, pp. 12131221, 2008.

[27] A. Nag, B. A. DeCarlo, and V. A. Rakov, "Analysis of microsecondand submicrosecond-scale electric field pulses produced by cloud and ground lightning discharges," Atmos. Res., vol. 91, pp. 316-325, 2009.

[28] J. S. Makela, N. Porjo, A. Makela, T. Tuomi, and V. Cooray, "Properties of preliminary breakdown processes in Scandinavian lightning," J. Atmos. Solar-Terr. Phys., vol. 70, pp. 2041-2052, 2008.

[29] M. Hayakawa, D. I. Iudin, and V. Y. Trakhtengerts, "Modeling of thundercloud VHF/UHF radiation of the lightning preliminary breakdown stage," J. Atmos. Solar-Terr. Phys., vol. 70, pp. 1660-1668, 2008.

[30] C. Gomes and V. Cooray, "Radiation field pulses associated with the initiation of positive cloud to ground lightning flashes," J. Atmos. SolarTerr. Phys., vol. 66, pp. 1047-1055, 2004.

[31] C. Gomes, V. Cooray, M. Fernando, R. Montano, and U. Sonnadara, "Characteristics of chaotic pulse trains generated by lightning flashes," J. Atmos. Solar-Terr. Phys., vol. 66, pp. 1733-1743, 2004.

[32] S. R. Sharma, M. Fernando, and C. Gomes, "Signatures of electric field pulses generated by cloud flashes," J. Atmos. Solar-Terr. Phys., vol. 67, pp. 413-422, 2005.

[33] U. Sonnadara, V. Cooray, and M. Fernando, "The lightning radiation field spectra of cloud flashes in the interval from $20 \mathrm{kHz}$ to $20 \mathrm{MHz}$,' 
IEEE Trans. Electromagn. Compat., vol. 48, no. 1, pp. 234-239, Feb. 2006.

[34] Y. Villanueva, V. A. Rakov, M. A. Uman, and M. Brook, "Microsecondscale electric field pulses in cloud lightning discharges," J. Geophys. Res., vol. 99, pp. 14353-14360, 1994.

[35] D. A. Smith, X. M. Shao, D. N. Holden, C. T. Rhodes, M. Brook, P. R. Krehbiel, M. Stanley, W. Rison, and R. J. Thomas, "A distinct class of isolated intracloud lightning discharges and their associated radio emissions," J. Geophys. Res., vol. 104, pp. 4189-4212, 1999.

[36] W. Rison, R. J. Thomas, P. R. Krehbiel, T. Hamlin, and J. Harlin, “A GPSbased three-dimensional lightning mapping system: Initial observations in central New Mexico," Geophys. Res. Lett., vol. 26, pp. 3573-3576, 1999.

[37] R. J. Thomas, P. R. Krehbiel, W. Rison, T. Hamlin, J. Harlin, and D. Shown, "Observations of VHF source powers radiated by lightning," Geophys. Res. Lett., vol. 28, pp. 143-146, 2001.

[38] D. A. Smith, M. J. Heavner, A. R. Jacobson, X. M. Shao, R. S. Massey, R. J. Sheldon, and K. C. Wiens, "A method for determining intracloud lightning and ionospheric heights from VLF/LF electric field records," Radio Sci., vol. 39, RS1010, 2004. DOI: 10.1029/2002RS002790.

[39] S. R. Sharma, M. Fernando, and V. Cooray, "Narrow positive bipolar radiation from lightning observed in Sri Lanka," J. Atmos. Solar-Terr. Phys., vol. 70, pp. 1251-1260, 2008.

[40] N. D. Murray, E. P. Krider, and J. C. Willett, "Multiple pulses in $\mathrm{dE} / \mathrm{dt}$ and the fine-structure of $\mathrm{E}$ during the onset of first return strokes in cloud-to-ocean lightning," Atmos. Res., vol. 76, pp. 455-480, 2005.

[41] J. Jerauld, M. A. Uman, V. A. Rakov, K. J. Rambo, and G. H. Schnetzer, "Insights into the ground attachment process of natural lightning gained from an unusual triggered-lightning stroke," J. Geophys. Res., vol. 112, pp. D13113-1-D13113-16, 2007. DOI: 10.1029/2006JD007682.

[42] V. Cooray, M. Fernando, C. Gomes, and T. Sorenssen, "The fine structure of positive lightning return-stroke radiation fields," IEEE Trans. Electromagn. Compat., vol. 46, no. 1, pp. 87-95, Feb. 2004

[43] B. H. Lee, J. H. Eom, S. M. Kang, S. K. Paek, and T. Kawamura, "Characteristics of the radiation field waveforms produced by lightning return strokes," Jpn. J. Appl. Phys., vol. 43, pp. 4379-4385, 2004.

[44] B. H. Lee, D. C. Jeong, D. M. Lee, and T. Kawamura, "Characteristics of the lightning stepped-leader electromagnetic pulses," Jpn. J. Appl. Phys., vol. 45, pp. 933-939, 2006.

[45] A. M. Hussein, M. Milewski, and W. Janischewskyj, "Correlating the characteristics of the $\mathrm{CN}$ tower lightning return-stroke current with those of its generated electromagnetic pulse," IEEE Trans. Electromagn. Compat., vol. 50, no. 3, pp. 642-650, Aug. 2008.

[46] M. Ishii and M. Saito, "Lightning electric field characteristics associated with transmission-line faults in winter," IEEE Trans. Electromagn. Compat., vol. 51, no. 3, pp. 459-465, Aug. 2009.

[47] M. Miki, V. A. Rakov, K. J. Rambo, G. H. Schnetzer, and M. A. Uman, "Electric fields near triggered lightning channels measured with Pockels sensors," J. Geophys. Res., vol. 107 (D16), pp. ACL2.1-ACL2.11, 2002. DOI: $10.1029 / 2001 J D 001087$.

[48] V. Jayakumar, V. A. Rakov, M. Miki, M. A. Uman, G. H. Schnetzer, and K. J. Rambo, "Estimation of input energy in rocket-triggered lightning," Geophys. Res. Lett., vol. 33, pp. L05702-1-L05702-4, 2006. DOI: $10.1029 / 2005$ GL025141.

[49] G. Maslowski and V. A. Rakov, "A study of the lightning-channel corona sheath," J. Geophys. Res., vol. 111, D14110, 2006. DOI: 10.1029/2005JD006858.

[50] V. A. Rakov and M. A. Uman, "Review and evaluation of lightning return stroke models including some aspects of their application," IEEE Trans. Electromagn. Compat., vol. 40, no. 4, pp. 403-426, Nov. 1998.

[51] F. Rachidi, V. A. Rakov, C. A. Nucci, and J. L. Bermudez, "The effect of vertically-extended strike object on the distribution of current along the lightning channel," J. Geophys. Res., vol. 107, 4699, 2002.

[52] A. S. Podgorski and J. A. Landt, "Three dimensional time domain modelling of lightning," IEEE Trans. Power Del., vol. PWRD-2, no. 3, pp. 931-938, Jul. 1987.

[53] Y. Baba and V. A. Rakov, "Electromagnetic models of the lightning return stroke," J. Geophys. Res., vol. 112, D04102, 2007. DOI: 10.1029/2006JD007222.

[54] S. Visacro, J. A. Soares, and M. A. O. Schroeder, "An interactive computational code for simulation of transient behavior of electric system components for lightning currents," presented at the 26th Int. Conf. Lightning Protection (ICLP), Cracow, Poland, 2002.
[55] Y. Baba and V. A. Rakov, "Applications of electromagnetic models of the lightning return stroke," IEEE Trans. Power Del., vol. 23, no. 2, pp. 800-811, Apr. 2008.

[56] S. Visacro and F. H. Silveira, "Evaluation of lightning current distribution along the lightning discharge channel by a hybrid electromagnetic model," J. Electrostat., vol. 60, pp. 111-120, 2004.

[57] S. Visacro and J. A. Soares, "HEM: A model for simulation of lightningrelated engineering problems," IEEE Trans. Power Del., vol. 20, no. 2, pp. 1206-1208, Apr. 2005.

[58] T. Miyazaki and M. Ishii, "Influence of independent towers and transmission lines on lightning return stroke current and associated fields," IEEE Trans. Electromagn. Compat., vol. 50, no. 2, pp. 358-368, May 2008.

[59] S. Bonyadi-Ram, R. Moini, S. H. H. Sadeghi, and V. A. Rakov, "On representation of lightning return stroke as a lossy monopole antenna with inductive loading," IEEE Trans. Electromagn. Compat., vol. 50, no. 1, pp. 118-127, Feb. 2008.

[60] Y. Baba and V. A. Rakov, "Electric and magnetic fields predicted by different electromagnetic models of the lightning return stroke versus measured fields," IEEE Trans. Electromagn. Compat., vol. 51, no. 3, pp. 479-487, Aug. 2009.

[61] S. S. Moosavi, R. Moini, and S. H. H. Sadeghi, "Representation of a lightning return-stroke channel as a nonlinearly loaded thin-wire antenna," IEEE Trans. Electromagn. Compat., vol. 51, no. 3, pp. 488-498, Aug. 2009.

[62] N. Theethayi and V. Cooray, "On the representation of the lightning return stroke process as a current pulse propagating along a transmission line," IEEE Trans. Power Del., vol. 20, no. 2, pp. 823-837, Apr. 2005.

[63] V. Cooray and N. Theethayi, "Pulse propagation along transmission lines in the presence of corona and their implication to lightning return strokes," IEEE Trans. Antennas Propag., vol. 56, no. 7, pp. 1948-1959, Jul. 2008.

[64] V. A. Rakov, "Lightning return stroke speed," J. Lightning Res., vol. 1, pp. 80-89, 2007.

[65] Y. Baba and V. A. Rakov, "On the mechanism of attenuation of current waves propagating along a vertical perfectly conducting wire above ground: Application to lightning," IEEE Trans. Electromagn. Compat., vol. 47, no. 3, pp. 521-532, Aug. 2005.

[66] S. Visacro and A. De Conti, "A distributed-circuit return-stroke model allowing time and height parameter variation to match lightning electromagnetic field," Geophys. Res. Lett., vol. 32, pp. L23805-1-L23805-5, 2005. DOI: $10.1029 / 2005$ GL024336.

[67] A. R. De Conti, S. Visacro, N. Theethayi, and V. Cooray, "A comparison of different approaches to simulate a nonlinear channel resistance in lightning return stroke models," J. Geophys. Res., vol. 113, pp. D141291-D14129-13, 2008.

[68] V. Cooray, "On the concepts used in return stroke models applied in engineering practice," IEEE Trans. Electromagn. Compat., vol. 45, no. 1, pp. 101-108, Feb. 2003.

[69] F. Rachidi and C. A. Nucci, "On the Master, Uman, Lin, Standler and the modified transmission line lightning return stroke current models," J. Geophys. Res., vol. 95, pp. 20389-20394, 1990.

[70] G. Maslowski and V. A. Rakov, "Equivalency of lightning return stroke models employing lumped and distributed current sources," IEEE Trans. Electromagn. Compat., vol. 49, no. 1, pp. 123-132, Feb. 2007.

[71] V. Cooray, V. A. Rakov, F. Rachidi, R. Montano, and C. A. Nucci, "On the relationship between the signature of close electric field and the equivalent corona current in lightning return stroke models," IEEE Trans. Electromagn. Compat., vol. 50, no. 4, pp. 921-927, Nov. 2008.

[72] G. Maslowski and V. A. Rakov, "New insights into lightning returnstroke models with specified longitudinal current distribution," IEEE Trans. Electromagn. Compat., vol. 51, no. 3, pp. 471-478, Aug. 2009.

[73] F. Rachidi, W. Janischewskyj, A. M. Hussein, C. A. Nucci, S. Guerrieri, B. Kordi, and J. S. Chang, "Current and electromagnetic field associated with lightning return strokes to tall towers," IEEE Trans. Electromagn. Compat., vol. 43, no. 3, pp. 356-367, Aug. 2001.

[74] Y. Baba and V. A. Rakov, "Lightning electromagnetic environment in the presence of a tall grounded strike object," J. Geophys. Res., vol. 110, pp. D09108-1-D09108-18, 2005.

[75] Y. Baba and V. A. Rakov, "On the use of lumped sources in lightning return stroke models," J. Geophys. Res., vol. 110, D03101, 2005.

[76] D. Pavanello, F. Rachidi, M. Rubinstein, J. L. Bermudez, W. Janischewskyj, V. Shostak, C. A. Nucci, A. M. Hussein, and J. S. Chang, "On return stroke currents and remote electromagnetic fields associated with 
lightning strikes to tall structures: Part I: Computational Models," $J$. Geophys. Res., vol. 112, pp. D13101-1-D13101-10, 2007.

[77] B. Kordi, R. Moini, W. Janischewskyj, A. Hussein, V. Shostak, and V. A. Rakov, "Application of the antenna theory model to a tall tower struck by lightning," J. Geophys. Res., vol. 108, no. D17, 4542, 2003.

[78] J. L. Bermudez, F. Rachidi, W. Janischewskyj, V. Shostak, M. Rubinstein, D. Pavanello, A. M. Hussein, J. S. Chang, C. A. Nucci, and M. Paolone, "Far-field-current relationship based on the TL model for lightning return strokes to elevated strike objects," IEEE Trans. Electromagn. Compat., vol. 47, no. 1, pp. 146-159, Feb. 2005.

[79] Y. Baba and V. A. Rakov, "Electromagnetic fields at the top of a tall building associated with nearby lightning return strokes," IEEE Trans. Electromagn. Compat., vol. 49, no. 3, pp. 632-643, Aug. 2007.

[80] Y. Baba and V. A. Rakov, "Influence of strike object grounding on close lightning electric fields," J. Geophys. Res., vol. 113, D12109, 2008. DOI: 10.1029/2008JD009811.

[81] A. Mosaddeghi, D. Pavanello, F. Rachidi, and A. Rubinstein, "On the inversion of polarity of the electric field at very close range from a tower struck by lightning," J. Geophys. Res., vol. 112, D19113, 2007.

[82] Y. Baba and V. A. Rakov, "Lightning strikes to tall objects: Currents inferred from far electromagnetic fields versus directly measured currents," Geophys. Res. Lett., vol. 34, L19810, 2007. DOI: 10.1029/2007GL030870.

[83] A. Lafkovici, A. M. Hussein, W. Janischewskyj, and K. L. Cummins, "Evaluation of the performance characteristics of the North American Lightning Detection Network based on tall-structure lightning," IEEE Trans. Electromagn. Compat., vol. 50, no. 3, pp. 630-641, Aug. 2008.

[84] D. Pavanello, F. Rachidi, W. Janischewskyj, M. Rubinstein, V. O. Shostak, C. A. Nucci, K. L. Cummins, A. M. Hussein, and J. S. Chang, "On the current peak estimates provided by lightning detection networks for lightning return strokes to tall towers," IEEE Trans. Electromagn. Compat., vol. 51, no. 3, pp. 453-458, Aug. 2009.

[85] J. Schoene, M. A. Uman, V. A. Rakov, K. J. Rambo, J. Jerauld, and G. H. Schnetzer, "Test of the transmission line model and the traveling current source model with triggered lightning return strokes at very close range," J. Geophys. Res., vol. 108, no. D23, 4737, 2003. DOI: 10.1029/2003JD003683

[86] S. Miyazaki and M. Ishii, "Reproduction of time derivative of electromagnetic field associated with rocket-triggered lightning in submicrosecond range," J. Geophys. Res., vol. 111, pp. D22203-1-D22203-9, 2006. DOI: $10.1029 / 2005 J D 006471$

[87] D. Pavanello, F. Rachidi, W. Janischewskyj, M. Rubinstein, A. M. Hussein, E. Petrache, V. Shostak, I. Boev, C. A. Nucci, W. A. Chisholm, M. Nyffeler, J. S. Chang, and A. Jaquier, "On return-stroke currents and remote electromagnetic fields associated with lightning strikes to tall structures. Part II: Experiment and model validation," J. Geophys. Res., vol. 112, D13122, 2007. DOI: 10.1029/2006JD007959.

[88] C. J. Biagi, K. L. Cummins, K. E. Kehoe, and E. P. Krider, "National lightning detection network (NLDN) performance in southern Arizona, Texas, and Oklahoma in 2003-2004," J. Geophys. Res., vol. 112, pp. D052081-D05208-17, 2007. DOI: 10.1029/2006JD007341.

[89] W. Schulz, K. L. Cummins, G. Diendorfer, and M. Dorninger, "Cloudto-ground lightning in Austria: A 10-year study using data from a lightning location system," J. Geophys. Res., vol. 110, D09101, 2005. DOI: 10.1029/2004JD005332.

[90] D. A. Smith, K. B. Eack, J. Harlin, M. J. Heavner, A. R. Jacobson, R. S. Massey, X. M. Shao, and K. C. Wiens, "The Los Alamos Sferic Array: A research tool for lightning investigations," J. Geophys. Res., vol. 107, D13, 2002. DOI: 10.1029/2001JD000502.

[91] X. M. Shao, M. Stanley, A. Regan, J. Harlin, M. Pongratz, and M. Stock, "Total lightning observations with the new and improved Los Alamos Sferic Array (LASA)," J. Atmos. Technol., vol. 23, pp. 1273-1288, 2006.

[92] X. M. Shao and A. Jacobson, "Model simulation of very low-frequency and low-frequency lightning signal propagation over intermediate ranges," IEEE Trans. Electromagn. Compat., vol. 51, no. 3, pp. 519525, Aug. 2009.

[93] A. Baños, Dipole Radiation in the Presence of a Conducting Half-Space. New York: Oxford, 1966.

[94] F. Delfino, R. Procopio, F. Rachidi, and C. A. Nucci, "An algorithm for the exact evaluation of the underground lightning electromagnetic fields," IEEE Trans. Electromagn. Compat., vol. 49, no. 2, pp. 401-411, May 2007.

[95] F. Delfino, R. Procopio, and M. Rossi, "Lightning return stroke current radiation in presence of a conducting ground: 1 . Theory and numerical evaluation of the electromagnetic fields," J. Geophys. Res., vol. 113, pp. D05110-1-D05110-10, 2008.

[96] F. Delfino, R. Procopio, M. Rossi, F. Rachidi, and C. A. Nucci, "Lightning return stroke current radiation in presence of a conducting ground: 2 . Validity assessment of simplified approaches," J. Geophys. Res., vol. 113 , pp. D05111-1-D05111-11, 2008

[97] P. A. Tirkas, C. A. Balanis, M. P. Purchine, and G. C. Barber, "Finitedifference time-domain method for electromagnetic radiation, interference, and interaction with complex structures," IEEE Trans. Electromagn. Compat., vol. 35, no. 2, pp. 192-203, May 1993.

[98] M. Paolone, C. A. Nucci, and F. Rachidi, "A new finite difference time domain scheme for the evaluation of lightning induced overvoltages on multiconductor overhead lines," presented at the 5th Int. Conf. Power Syst. Transients, Rio de Janeiro, Brazil, 2001.

[99] C. A. F. Sartori and J. R. Cardoso, "An analytical-FDTD method for near LEMP calculation," IEEE Trans. Magn., vol. 36, no. 4, pp. 1631-1634, Jul. 2000

[100] C. Yang and B. Zhou, "Calculation methods of electromagnetic fields very close to lightning," IEEE Trans. Electromagn. Compat., vol. 46 , no. 1, pp. 133-141, Feb. 2004.

101] Y. Baba and V. A. Rakov, "On the interpretation of ground reflections observed in small-scale experiments simulating lightning strikes to towers," IEEE Trans. Electromagn. Compat., vol. 47, no. 3, pp. 533-542, Aug. 2005.

[102] F. Heidler and T. Zundl, "Influence of tall towers on the return stroke current," presented at the Aerosp. Ground Conf. Lightning Static Electr., Williamsburg, VA, 1995.

[103] R. Moini, V. A. Rakov, M. A. Uman, and B. Kordi, "An antenna theory model for the lightning return stroke," in Proc. 12th Int. Zurich Symp. Electromagn. Compat., Zurich, Switzerland, 1997, pp. 149-152.

[104] R. Moini, B. Kordi, G. Z. Rafi, and V. A. Rakov, "A new lightning return stroke model based on antenna theory," J. Geophys. Res., vol. 105, pp. 29693-29702, 2000.

[105] Y. Baba and M. Ishii, "Numerical electromagnetic field analysis of lightning current in tall structures," IEEE Trans. Power Del., vol. 16, no. 2, pp. 324-328, Apr. 2001.

[106] E. Petrache, F. Rachidi, D. Pavanello, W. Janischewskyj, A. M. Hussein, M. Rubinstein, V. Shostak, W. A. Chisholm, and J. S. Chang, "Lightning strikes to elevated structures: Influence of grounding conditions on currents and electromagnetic fields," presented at the IEEE Int. Symp. Electromagn. Compat., Chicago, IL, 2005.

[107] A. Shoory, R. Moini, S. H. H. Sadeghi, and V. A. Rakov, "Analysis of lightning-radiated electromagnetic fields in the vicinity of lossy ground," IEEE Trans. Electromagn. Compat., vol. 47, no. 1, pp. 131-145, Feb. 2005.

[108] M. A. Uman, D. K. McLain, and E. P. Krider, "The electromagnetic radiation from a finite antenna," Amer. J. Phys., vol. 43, pp. 33-38, 1975.

[109] M. Rubinstein, "An approximate formula for the calculation of the horizontal electric field from lightning at close, intermediate, and long range," IEEE Trans. Electromagn. Compat., vol. 38, no. 3, pp. 531-535, Aug. 1996.

[110] A. Zeddam and P. Degauque, "Current and voltage induced on telecommunications cable by a lightning return stroke," in Lightning Electromagnetics, R. L. Gardner, Ed. New York: Hemisphere, 1990, pp. 37740.

[111] F. Rachidi, C. A. Nucci, M. Ianoz, and C. Mazzetti, "Influence of a lossy ground on lightning-induced voltages on overhead lines," IEEE Trans. Electromagn. Compat., vol. 38, no. 3, pp. 250-264, Aug. 1996.

[112] A. K. Agrawal, H. J. Price, and S. H. Gurbaxani, "Transient response of multiconductor transmission lines excited by a nonuniform electromagnetic field," IEEE Trans. Electromagn. Compat., vol. 22, no. 2, pp. 119-129, May 1980.

[113] J. R. Wait, "Concerning the horizontal electric field of lightning," IEEE Trans. Electromagn. Compat., vol. 39, no. 2, p. 186, May 1997.

[114] C.F. Barbosa and J. O. S. Paulino, "An approximate time-domain formula for the calculation of the horizontal electric field from lightning," IEEE Trans. Electromagn. Compat., vol. 49, no. 3, pp. 593-601, Aug. 2007.

[115] C. Caligaris, F. Delfino, and R. Procopio, "Cooray-Rubinstein formula for the evaluation of lightning radial electric fields: Derivation and implementation in the time domain," IEEE Trans. Electromagn. Compat., vol. 50, no. 1, pp. 194-197, Feb. 2008.

[116] V. Cooray, "Underground electromagnetic fields generated by the return strokes of lightning flashes," IEEE Trans. Electromagn. Compat., vol. 43, no. 1, pp. 75-84, Feb. 2001. 
[117] E. Petrache, F. Rachidi, M. Paolone, C. Nucci, V. A. Rakov, and M. A. Uman, "Lightning-induced voltages on buried cables. Part I: Theory," IEEE Trans. Electromagn. Compat., vol. 47, no. 3, pp. 498-508, Aug. 2005.

[118] A. Mimouni, F. Rachidi, and Z. Azzouz, "Electromagnetic environment in the immediate vicinity of a lightning return stroke," J. Lightning Res., vol. 2, pp. 64-75, 2007.

[119] A. Mimouni, F. Rachidi, and Z. Azzouz, "A finite-difference timedomain approach for the evaluation of electromagnetic fields radiated by lightning to tall structures," J. Electrostat., vol. 866, pp. 504-513, 2008.

[120] R. Thottappillil and V. A. Rakov, "On different approaches to calculating lightning electric fields," J. Geophys. Res., vol. 106, pp. 14191-14205, 2001.

[121] R. Thottappillil, V. A. Rakov, and N. Theethayi, "Expressions for far electric fields produced at an arbitrary altitude by lightning return strokes," J. Geophys. Res., vol. 112, pp. D16102-1-D16102-8, 2007. DOI: 10.1029/2007JD008559.

[122] V. A. Rakov and W. G. Tuni, "Lightning electric field intensity at high altitudes: Inferences for production of elves," J. Geophys. Res., vol. 108, no. D20, 4639, 2003. DOI: 10.1029/2003JD003618.

[123] X. M. Shao, A. R. Jacobson, and T. J. Fitzgerald, "Radio frequency radiation beam pattern of lightning return strokes: A revisit to theoretical analysis," J. Geophys. Res., vol. 109, pp. D19108-1-D19108-4, 2004 DOI: $10.1029 / 2004 J D 004612$.

[124] M. Fernando and V. Cooray, "Propagation effects on the electric field time derivatives generated by return strokes in lightning flashes," $J$. Atmos. Solar-Terr. Phys., vol. 69, pp. 1388-1396, 2007.

[125] V. Cooray, "Propagation effects on radiation field pulses generated by cloud lightning flashes," J. Atmos. Solar-Terr. Phys., vol. 69, pp. 13971406, 2007.

[126] V. Cooray, "On the accuracy of several approximate theories used in quantifying the propagation effects on lightning generated electromagnetic fields," IEEE Trans. Antennas Propag., vol. 56, no. 7, pp. 19601967, Jul. 2008.

[127] V. Cooray, "Propagation effects due to finitely conducting ground on lightning-generated magnetic fields using Sommerfeld's integrals," IEEE Trans. Electromagn. Compat., vol. 51, no. 3, pp. 526-531, Aug. 2009

[128] F. M. Tesche, "Comparison of the transmission line and scattering models for computing the HEMP response of overhead cables," IEEE Trans. Electromagn. Compat., vol. 34, no. 2, pp. 93-99, May 1992.

[129] C. A. Nucci, F. Rachidi, and M. Rubinstein, "Derivation of telegrapher's equations and field-to-transmission line interaction," in Electromagnetic Field Interaction with Transmission Lines: From Classical Theory to HF Radiation Effects, F. Rachidi and S. Tkachenko, Eds., Southampton, U.K.: WIT Press, 2008, pp. 3-22.

[130] C. D. Taylor, R. S. Satterwhite, and C. W. Harrison, "The response of a terminated two-wire transmission line excited by a nonuniform electromagnetic field," IEEE Trans. Antennas Propag., vol. AP-13, no. 6, pp. 987-989, Nov. 1965.

[131] F. Rachidi, "Formulation of the field-to-transmission line coupling equations in terms of magnetic excitation fields," IEEE Trans. Electromagn. Compat., vol. 35, no. 3, pp. 404-407, Aug. 1993.

[132] C. Nucci and F. Rachidi, "Interaction of electromagnetic fields generated by lightning with overhead electrical networks," in The Lightning Flash, V. Cooray, Ed. London, U.K.: IEE, 2003, pp. 425-478.

[133] R. Montano, N. Theethayi, and V. Cooray, "An efficient implementation of the Agrawal et al. model for lightning-induced voltage calculations using circuit simulation software," IEEE Trans. Circuits Syst. I: Reg. Papers, vol. 55, no. 9, pp. 2959-2965, Oct. 2008.

[134] H. K. Hoidalen, "Analytical formulation of lightning-induced voltages on multiconductor overhead lines above lossy ground," IEEE Trans. Electromagn. Compat., vol. 45, no. 1, pp. 92-100, Feb. 2003.

[135] M. Darveniza, “A practical extension of Rusck's formula for maximum lightning induced voltage that accounts for ground resistivity," IEEE Trans. Power Del., vol. 22, no. 1, pp. 605-612, Jan. 2007.

[136] R. K. Pokharel, M. Ishii, and Y. Baba, "Numerical electromagnetic analysis of lightning-induced voltage over ground of finite conductivity," IEEE Trans. Electromagn. Compat., vol. 45, no. 4, pp. 651-656, Nov. 2003.

[137] R. K. Pokharel, Y. Baba, and M. Ishii, "Numerical electromagnetic analysis of transient induced voltages associated with lightning to tall structure," J. Electrostat., vol. 60, pp. 141-147, 2004.

[138] Y. Baba and V. A. Rakov, "Voltages induced on an overhead wire by lightning strikes to a nearby tall grounded object," IEEE Trans. Electromagn. Compat., vol. 48, no. 1, pp. 212-224, Feb. 2006.
[139] H. M. Ren, B. H. Zhou, V. A. Rakov, L. H. Shi, C. Gao, and J. H. Yang, "Analysis of lightning-induced voltages on overhead lines using a 2-D FDTD method and Agrawal coupling model," IEEE Trans. Electromagn. Compat., vol. 50, no. 3, pp. 651-659, Aug. 2008.

[140] K. Michishita, M. Ishii, A. Asakawa, S. Yokoyama, and K. Kami, "Voltage induced on a test distribution line by negative winter lightning strokes to a tall structure," IEEE Trans. Electromagn. Compat., vol. 45, no. 1, pp. 135-140, Feb. 2003

[141] N. Theethayi and R. Thottappillil, "Surge propagation and crosstalk in multiconductor transmission lines above ground," in Electromagnetic Field Interaction With Transmission Lines. From Classical Theory to HF Radiation Effects, F. Rachidi and S. Tkachenko, Eds., Southampton, U.K.: WIT Press, 2008.

[142] M. Paolone, F. Rachidi, A. Borghetti, C. A. Nucci, M. Rubinstein, V. A. Rakov, and M. A. Uman, "Lightning electromagnetic field coupling to overhead lines: Theory, numerical simulations, and experimental validation," IEEE Trans. Electromagn. Compat., vol. 51, no. 3, pp. 532-548, Aug. 2009.

[143] N. Theethayi, R. Thottappillil, T. Yirdaw, Y. Liu, T. Götschl, and R. Montano, "Experimental investigation of lightning transients entering a Swedish railway facility," IEEE Trans. Power Del., vol. 22, no. 1, pp. 354-363, Jan. 2007

[144] A. Borghetti, A. S. Morched, F. Napolitano, C. A. Nucci, and M. Paolone, "Lightning-induced overvoltages transferred through distribution power transformers," IEEE Trans. Power Del., vol. 24, no. 1, pp. 360-372, Jan. 2009.

[145] M. Paolone, E. Petrache, F. Rachidi, C. A. Nucci, V. A. Rakov, M. A. Uman, D. Jordan, K. Rambo, J. Jerauld, M. Nyffeler, and J. Schoene, "Lightning-induced voltages on buried cables. Part II: Experiment and model validation," IEEE Trans. Electromagn. Compat., vol. 47, no. 3, pp. 509-520, Aug. 2005.

[146] E. Petrache, M. Paolone, F. Rachidi, C. A. Nucci, V. A. Rakov, M. A. Uman, D. Jordan, K. Rambo, J. Jerauld, M. Nyffeler, and J. Schoene, "Lightning-induced currents in buried coaxial cables: A frequencydomain approach and its validation using rocket-triggered lightning," J. Electrostat., vol. 65, pp. 322-328, May 2007.

[147] N. Theethayi, R. Thottappillil, M. Paolone, C. A. Nucci, and F. Rachidi, "External impedance and admittance of buried horizontal wires for transient studies using transmission line analysis," IEEE Trans. Dielectr. Electr. Insul., vol. 14, no. 3, pp. 751-761, Jun. 2007.

[148] Y. H. Zhou, L. H. Shi, C. Gao, B. H. Zhou, and B. Chen, "Combination of FDTD method with digital filter in analyzing the field-to-transmission line coupling," IEEE Trans. Electromagn. Compat., vol. 50, no. 4, pp. 1003-1007, Nov. 2008.

[149] J. Schoene, M. A. Uman, V. A. Rakov, J. Jerauld, B. D. Hanley, K. J. Rambo, J. Howard, and B. A. DeCarlo, "Lightning-induced currents in a buried loop conductor and a grounded vertical conductor," IEEE Trans. Electromagn. Compat., vol. 50, no. 1, pp. 110-117, Feb. 2008.

[150] M. Bejleri, V. A. Rakov, M. A. Uman, K. J. Rambo, C. T. Mata, and M. I. Fernandez, "Triggered lightning testing of an airport runway lighting system," IEEE Trans. Electromagn. Compat., vol. 46, no. 1, pp. 96-101, Feb. 2004

[151] N. Theethayi, V. A. Rakov, and R. Thottappillil, "Responses of airport runway lighting system to direct lightning strikes: Comparisons of TLM predictions with experimental data," IEEE Trans. Electromagn. Compat., vol. 50, no. 3, pp. 660-668, Aug. 2008.

[152] N. Theethayi, Y. Baba, F. Rachidi, and R. Thottappillil, "On the choice between transmission line equations and full-wave Maxwell's equations for transient analysis of buried wires," IEEE Trans. Electromagn. Compat., vol. 50, no. 2, pp. 347-357, May 2008.

[153] M. A. Uman, The Art and Science of Lightning Protection. New York, Cambridge Univ. Press, 2008.

[154] IEEE Guide for Improving the Lightning Performance of Electric Power Overhead Distribution Lines, IEEE Standard 1410, 2004.

[155] CIGRE-CIRED JWG C4.4.02: Protection of MV and LV Networks Against Lightning. Part I: Common Topics, CIGRE Tech. Brochure No. 287, 2006.

[156] I. A. Metwally and F. Heidler, "Improvement of lightning shielding performance of overhead transmission lines by passive shield wires," IEEE Trans. Electromagn. Compat., vol. 45, no. 2, pp. 378-392, May 2003.

[157] M. Paolone, C. A. Nucci, E. Petrache, and F. Rachidi, "Mitigation of lightning-induced overvoltages in medium voltage distribution lines by means of periodical grounding of shielding wires and of surge arresters: Modelling and experimental validation," IEEE Trans. Power Del., vol. 19, no. 1, pp. 423-431, Jan. 2004 
[158] S. Rusck, "Induced lightning overvoltages on power transmission lines with special reference to the overvoltage protection of low voltage networks," Trans. R. Inst. Technol., vol. 120, 1958.

[159] A. Piantini and J. M. Janiszewski, "The effectiveness of surge arresters on the mitigation of lightning induced voltages on distribution lines," in Proc. 8th Int. Symp. Lightning Protection (SIPDA), Sao Paulo, Brazil, 2005, pp. 777-798.

[160] A. Piantini, J. M. Janiszewski, A. Borghetti, C. A. Nucci, and M. Paolone, "A scale model for the study of the LEMP response of complex power distribution networks," IEEE Trans. Power Del., vol. 22, no. 1, pp. 710720, Jan. 2007.

[161] A. Borghetti, C. A. Nucci, and M. Paolone, "An improved procedure for the assessment of overhead line indirect lightning performance and its comparison with the IEEE Std. 1410 method," IEEE Trans. Power Del., vol. 22, no. 1, pp. 684-692, Jan. 2007.

[162] T. Hirai, S. Miyazaki, K. Aiba, and S. Okabe, "Analysis of lightning phenomena observed in distribution lines," in Proc. 28th Int. Conf. Lightning Protection (ICLP), Kanazawa, Japan, 2006, pp. 778-782.

[163] T. Miyazaki, S. Okabe, and S. Sekioka, "An experimental validation of lightning performance in distribution lines," IEEE Trans. Power Del., vol. 23, no. 4, pp. 2182-2190, Oct. 2008.

[164] T. Miyazaki and S. Okabe, "A detailed field study of lightning stroke effects on distribution lines," IEEE Trans. Power Del., vol. 24, no. 1, pp. 352-359, Jan. 2009.

[165] I. Cotton, B. McNiff, T. Sorensen, W. Zischank, P. Christiansen, M. Hoppe-Kipler, S. Ramakers, P. Pettersen, and E. Muljadi, "Lightning protection for wind turbines," presented at the 25th Int. Conf. Lightning Protection (ICLP), Rhodes, Greece, 2000.

[166] I. Cotton, N. Jenkins, and K. Pandiaraj, "Lightning protection for wind turbine blades and bearings," Wind Energy, vol. 4, pp. 23-27, 2001.

[167] D. Agoris, K. Rossi, P. Vionis, N. Stavridis, and E. Ligons, "Analysis of lightning incidents on wind turbines in Greece," presented at the 26th Int. Conf. Lightning Protection (ICLP), Cracow, Poland, 2002.

[168] S. Yokoyama, "Lightning damages of wind turbine blades and protection methods of them," Trans. Inst. Electr. Eng. Jpn. B, vol. 124, pp. 77-180, 2004.

[169] M. Paolone, F. Napolitano, A. Borghetti, C. A. Nucci, M. Marzinotto, F. Fiamingo, C. Mazzetti, and H. Dellago, "Models of wind-turbine main shaft bearings for the development of specific lightning protection systems," presented at the IEEE Power Tech Conf., Lausanne, Switzerland, 2007.

[170] B. Glushakow, "Effective lightning protection for wind turbine generators," IEEE Trans. Energy Convers., vol. 22, no. 1, pp. 214-222, Mar. 2007.

[171] Wind Turbine Generator Systems-Part 24: Lightning Protection, International Electrotechnical Commission (IEC) 61400-24, Geneva, Switzerland, 2002.

[172] F. Rachidi, M. Rubinstein, J. Montanya, J. L. Bermudez, R. Rodriguez, G. Sola, and N. Korovkin, "A review of current issues in lightning protection of new generation wind turbine blades," IEEE Trans. Ind. Electron., vol. 55, no. 6, pp. 2489-2496, Jun. 2008.

[173] Y. Liu, M. Zitnik, and R. Thottappillil, "An improved transmissionline model of grounding system," IEEE Trans. Electromagn. Compat., vol. 43, no. 3, pp. 348-355, Aug. 2001.

[174] J. He, R. Zeng, Y. Tu, J. Zou, S. Chen, and Z. Guan, "Laboratory investigation of impulse characteristics of transmission tower grounding devices," IEEE Trans. Power Del., vol. 18, no. 3, pp. 994-1001, Jul. 2003.

[175] M. I. Lorentzou, N. D. Hatziargyriou, and B. C. Papadias, "Time domain analysis of grounding electrodes impulse response," IEEE Trans. Power Del., vol. 18, no. 2, pp. 517-524, Apr. 2003.

[176] Y. Liu, N. Theethayi, and R. Thottappillil, "An engineering model for transient analysis of grounding system under lightning strikes: Nonuniform transmission-line approach," IEEE Trans. Power Del., vol. 20, no. 2, pp. 722-730, Apr. 2005.

[177] J. He, Y. Gao, R. Zeng, J. Zou, X. Liang, B. Zhang, J. Lee, and S. Chang, "Effective length of counterpoise wire under lightning current," IEEE Trans. Power Del., vol. 20, no. 2, pp. 1585-1591, Apr. 2005.

[178] S. Visacro, "A comprehensive approach to the grounding response to lightning currents," IEEE Trans. Power Del., vol. 22, no. 1, pp. 381386, Jan. 2007.

[179] H. Motoyama, "Electromagnetic transient response of buried bare wire and ground grid," IEEE Trans. Power Del., vol. 22, no. 3, pp. 1673-1679, Jul. 2007.

[180] N. Theethayi, R. Thottappillil, G. Diendorfer, M. Mair, and H. Pichler, "Currents in buried grounding strips connected to communication tower legs during lightning strikes," IEEE Trans. Dielectr. Electr. Insul., vol. 15 no. 4, pp. 1153-1161, Aug. 2008.

[181] L. Grcev, "Impulse efficiency of ground electrodes," IEEE Trans. Power Del., vol. 24, no. 1, pp. 441-451, Jan. 2009.

[182] L. Grcev, "Modeling of grounding electrodes under lightning currents," IEEE Trans. Electromagn. Compat., vol. 51, no. 3, pp. 559-571, Aug. 2009.

[183] J. Wang, A. C. Liew, and M. Darveniza, "Extension of dynamic model of impulse behavior of concentrated grounds at high currents," IEEE Trans. Power Del., vol. 20, no. 3, pp. 2160-2165, Jul. 2005.

[184] S. Sekioka, T. Sonoda, and A. Ametani, "Experimental study of currentdependent grounding resistance of rod electrode," IEEE Trans. Power Del., vol. 20, no. 2, pp. 1569-1576, Apr. 2005.

[185] N. M. Nor, "Review: Soil electrical characteristics under high impulse currents," IEEE Trans. Electromagn. Compat., vol. 48, no. 4, pp. 826829, Nov. 2006.

[186] N. M. Nor, A. Haddad, and H. Griffiths, "Characterization of ionization phenomena in soils under fast impulses," IEEE Trans. Power Del., vol. 21, no. 1, pp. 353-361, Jan. 2006.

[187] S. Sekioka, M. I. Lorentzou, M. P. Philippakou, and J. M. Prousalidis, "Current-dependent grounding resistance model based on energy balance of soil ionization," IEEE Trans. Power Del., vol. 21, no. 1, pp. 194-201, Jan. 2006.

[188] A. Habjanic and M. Trlep, "The simulation of soil ionization phenomenon around the grounding system by the finite element method," IEEE Trans. Magn., vol. 42, no. 4, pp. 867-870, Apr. 2006.

[189] K. Sheshyekani, S. H. H. Sadeghi, and R. Moini, "Frequency-domain analysis of grounding electrodes buried in an ionized soil due to lightning surge currents," presented at the 29th Int. Conf. Lightning Protection (ICLP), Uppsala, Sweden, 2008.

[190] V. A. Rakov and M. A. Uman, Lightning: Physics and Effects. Cambridge, U.K.: Cambridge Univ. Press, 2003.

[191] V. A. Rakov, M. A. Uman, M. I. Fernandez, C. T. Mata, K. T. Rambo, M. V. Stapleton, and R. R. Sutil, "Direct lightning strikes to the lightning protective system of a residential building: Triggered-lightning experiments," IEEE Trans. Power Del., vol. 17, no. 2, pp. 575-586, Apr. 2002.

[192] B. A. DeCarlo, V. A. Rakov, J. Jerauld, G. H. Schnetzer, J. Schoene, M. A. Uman, K. J. Rambo, V. Kodali, D. M. Jordan, G. Maxwell, S. Humeniuk, and M. Morgan, "Distribution of currents in the lightning protective system of a residential building - Part I: Triggered-lightning experiments," IEEE Trans. Power Del., vol. 23, no. 4, pp. 2439-2446, Oct. 2008.

[193] L. Li and V. A. Rakov, "Distribution of currents in the lightning protective system of a residential building-Part II: Numerical modeling," IEEE Trans. Power Del., vol. 23, no. 4, pp. 2447-2455, Oct. 2008.

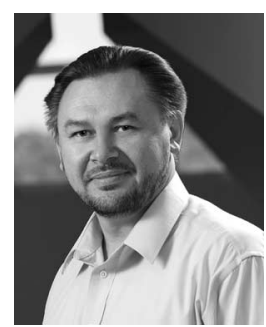

Vladimir A. Rakov (SM'96-F'03) received the M.S. and $\mathrm{Ph} . \mathrm{D}$. degrees in electrical engineering from Tomsk Polytechnical University (Tomsk Polytechnic), Tomsk, Russia, in 1977 and 1983, respectively.

From 1977 to 1979, he was an Assistant Professor of electrical engineering at Tomsk Polytechnic. From 1978, he was engaged in lightning research at the High Voltage Research Institute (a division of Tomsk Polytechnic), where he was the Director of the Lightning Research Laboratory from 1984 to 1994 . He is currently a Professor in the Department of Electrical and Computer Engineering, University of Florida, Gainesville, where he is also a Co-Director of the International Center for Lightning Research and Testing (ICLRT) and Chair of Electromagnetics and Energy Systems Division. He is the lead author of one book Lightning: Physics and Effects, and has authored or coauthored more than 500 other publications on various aspects of lightning with over 160 papers being published in reviewed journals. He is an Editor or an Associate Editor of four technical journals

Dr. Rakov is the Chairman of the Technical Committee on Lightning of the Biennial International Zurich Symposium on Electromagnetic Compatibility, a Co-Chairman of the International Union of Radio Science (URSI) Working Group (WG) E.4 "Lightning Discharges and Related Phenomena," and the Convener of the International Council on Large Electric Systems (CIGRE) WG C4-407 "Lightning Parameters for Engineering Applications." He is a Fellow of the American Meteorological Society (AMS) and the Institution of Engineering and Technology (formerly IEE). 


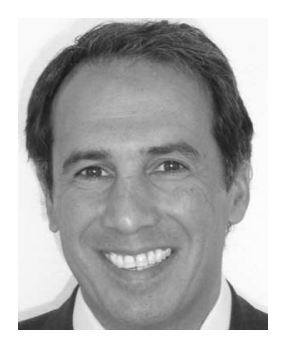

Farhad Rachidi (M'93-SM'02) received the M.S degree in electrical engineering and the Ph.D. degree from the Swiss Federal Institute of Technology, Lausanne, Switzerland, in 1986 and 1991, respectively.

Until 1996, he was with the Power Systems Laboratory, Swiss Federal Institute of Technology, where he is currently the Head of the Electromagnetic Compatibility Group. During 1997, he joined the Lightning Research Laboratory, University of Toronto, Canada. From April 1998 until September 1999, he was with Montena EMC, Switzerland. He is the Deputy Editor-in-Chief of the Journal of Lightning Research. He has authored or coauthored more than 250 scientific papers published in reviewed journals and presented at international conferences.

Dr. Rachidi is the Vice Chair of the European COST Action on the Physics of Lightning Flash and its Effects. He is the President of the International Conference on Lightning Protection. He is an Associate Editor of the IEEE TRANSACTIONS ON ELECTROMAGNETIC COMPATIBILITY. In 2005, he was the recipient of the IEEE Technical Achievement Award and the International Council on Large Electric Systems (CIGRE) Technical Committee Award. He received the 2006 Blondel Medal from the French Association of Electrical Engineering, Electronics, Information Technology and Communication (SEE).

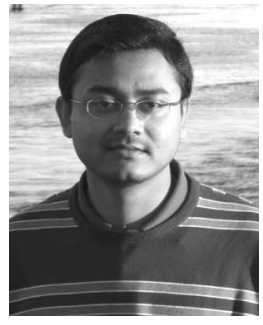

Amitabh Nag (M'04) received the M.S. degree in electrical engineering in 2007 from the University of Florida, Gainesville, where he is currently working towards the Ph.D. degree. Since 2005, he has been a Research Assistant at the International Center for Lightning Research and Testing (ICLRT), University of Florida, in-charge of the Lightning Observatory in Gainesville. He is the author or coauthor of over 20 papers and technical reports on various aspects of lightning, with five papers being published in reviewed journals. His current research interests include measurement, analysis, and modeling of electric and magnetic fields from cloud and ground lightning discharges and lightning detection.

Mr. Nag is a member of the American Meteorological Society (AMS) and the American Geophysical Union (AGU). 